\title{
Article
}

\section{Benchmark eye movement effects during natural reading in autism spectrum disorder}

\author{
Howard, Philippa, Liversedge, Simon Paul and Benson, Valerie \\ Available at https://clok.uclan.ac.uk/22339/ \\ Howard, Philippa, Liversedge, Simon Paul orcid iconORCID: 0000-0002-8579- \\ 8546 and Benson, Valerie orcid iconORCID: 0000-0002-0351-4563 (2017) \\ Benchmark eye movement effects during natural reading in autism spectrum \\ disorder. Journal of Experimental Psychology: Learning, Memory, and \\ Cognition, 43 (1). pp. 109-127. ISSN 0278-7393
}

It is advisable to refer to the publisher's version if you intend to cite from the work. http://dx.doi.org/10.1037/xIm0000289

For more information about UCLan's research in this area go to http://www.uclan.ac.uk/researchgroups/ and search for <name of research Group>.

For information about Research generally at UCLan please go to http://www.uclan.ac.uk/research/

All outputs in CLoK are protected by Intellectual Property Rights law, including Copyright law. Copyright, IPR and Moral Rights for the works on this site are retained by the individual authors and/or other copyright owners. Terms and conditions for use of this material are defined in the policies page.

\section{CLoK}

Central Lancashire online Knowledge www.clok.uclan.ac.uk

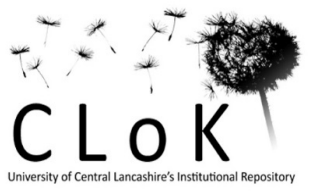


Benchmark Eye Movement Effects during Natural Reading in Autism Spectrum Disorder.

Philippa L. Howard*, Simon P. Liversedge \& Valerie Benson University of Southampton

*Corresponding author: PLH1G11@ soton.ac.uk

Psychology

Shackleton Building (B44)

Highfield Campus

University of Southampton

Southampton

SO17 1BJ 


\begin{abstract}
In two experiments, eye tracking methodology was used to assess online lexical, syntactic and semantic processing in autism spectrum disorder (ASD). In Experiment 1, lexical identification was examined by manipulating the frequency of target words. Both typically developed (TD) and ASD readers showed normal frequency effects, suggesting that the processes TD and ASD readers engage in to identify words are comparable. In Experiment 2, syntactic parsing and semantic interpretation requiring the online use of world knowledge were examined, by having participants read garden path sentences containing an ambiguous prepositional phrase. Both groups showed normal garden path effects when reading low attached sentences and the time course of reading disruption was comparable between groups. This suggests that not only do ASD readers hold similar syntactic preferences to TD readers, but also that they use world knowledge online during reading. Together, these experiments demonstrate that the initial construction of sentence interpretation appears to be intact in ASD. However, the finding that ASD readers skip target words less often in Experiment 2, and take longer to read sentences during second pass for both experiments, suggests that they adopt a more cautious reading strategy and take longer to evaluate their sentence interpretation prior to making a manual response.

Key phrases: Autism Spectrum Disorder, Reading, Eye Movements, Lexical Identification, Syntactic Ambiguity Resolution.
\end{abstract}


Benchmark Eye Movement Effects during Natural Reading in Autism Spectrum Disorder.

Autism spectrum disorder (ASD) is characterised by restrictive and repetitive patterns of behaviour and significant impairments in social interaction/communication (American Psychiatric Association, 2013). The cognitive differences that underpin this behavioural phenotype are often found to affect reading ability (e.g. Nation, Clarke, Wright, \& Williams, 2006). Individuals with ASD who do not have an associated learning difficulty or those who have Asperger syndrome, in general, are found to have intact performance accuracy for 'low level', basic reading tasks (e.g. word identification; Frith \& Snowling, 1983; Huemer \& Mann, 2010; Mayes \& Calhoun, 2006; Minshew, Goldstein, \& Siegel, 1995; Saldaña, Carreiras, \& Frith, 2009), but frequently display impairments in performance for 'higher order' reading tasks (e.g. text comprehension and inferencing; Huemer \& Mann, 2010; Jolliffe \& Baron-Cohen, 1999, 2000; Jones et al. 2009; Minshew et al. 1995; but see also Asberg, Kopp, Berg-Kelly, \& Gillberg, 2010).

As yet, there has been no specific theoretical explanation put forward to explain how linguistic processing occurs in ASD. Previous hypotheses as to why performance on higher order linguistic tasks is impaired have been derived from domain general cognitive accounts of ASD. The Weak Central Coherence Theory (WCC) claims ASD to result in a local processing bias coupled with a lack of spontaneous strive for global coherence (Frith, 1989; Frith \& Happé, 1994; Happé \& Frith, 2006). In the context of reading this would suggest that individuals with ASD may not integrate information within and between sentences. Evidence for this lack of contextual/global processing during reading has most notably been demonstrated using the homograph task. The homograph task involves participants reading sentences aloud that contain a heterophonic homograph (i.e., a word with one spelling, but two meanings and pronunciations) and readers with ASD have been reported to identify and pronounce the dominant meaning of the homograph, regardless of sentence context (Frith \& 
Snowling, 1983; Happe, 1997; Jolliffe \& Baron-Cohen, 1999; Lopez \& Leekam, 2003 c.f., Snowling \& Frith, 1986). However, the validity of these studies has been criticised (e.g., Brock \& Bzishili, 2013; Brock \& Caruana, 2014) and when other paradigms are adopted the findings of impaired integration during reading tasks is inconsistent, with some researchers finding poorer performance for individuals with ASD (e.g., Jolliffe \& Baron-Cohen, 1999; 2000), whereas others do not (e.g., Au-Yeung, Kaakinen, Liversedge \& Benson, 2015; Hala, Pexman \& Glenwright., 2007). The Theory of Complex Information Processing (CIP; Minshew \& Goldstein, 1998; Minshew, Goldstein \& Siegel, 1997; Minshew, Williams \& McFadden, 2008) proposes low level 'simple' processes to be intact in ASD, but 'complex' processes that require the integration of information or the use of top down knowledge, to be impaired. The evidence in support of this theory in relation to reading stems from studies showing that adults and children with ASD perform comparably to matched controls on batteries of standardised reading assessments that are defined as 'simple' (i.e., tasks that are rule based and can be completed upon the basis of information explicitly stated in the text e.g., word identification and grammar). In contrast performance is poorer compared to controls at reading tasks that are defined as 'complex' (i.e., tasks that require processing beyond explicit text information e.g., inferencing and comprehension, Minshew et al., 1995; Minshew \& Goldstein, 1998; Williams, Goldstein \& Minshew, 2006).

The majority of research examining reading in ASD has focused on accuracy and reaction time measures of performance. Although these studies are informative in relation to offline reading performance, they provide little insight into specific aspects of online cognitive processing associated with reading impairments in ASD. In the present work, we recorded participants' eye movements as they read naturally, to gain an insight into the online linguistic processing of written language in ASD. A literature search indicated that only three peer-reviewed articles have adopted this approach when examining natural reading in ASD 
(Au-Yeung et al., 2015; Caruana \& Brock, 2014; Sansosti, Was, Rawson, \& Remaklus, 2013). This is the case, even though eye movement recording is one of the most widespread methods used to examine reading in a typical population (e.g. Rayner, 1998; 2009).

The first study that used eye movements to examine reading in ASD was conducted by Sansosti et al., (2013) who partially replicated an experiment originally conducted by Saldaña and Frith (2007), whereby a group of children and adolescents with ASD read vignettes consisting of two sentences, designed to invoke a bridging inference. Each vignette either evoked an inference that required social or spatial knowledge and was followed by a general knowledge question that was either related (e.g. 1a) or unrelated (e.g. 1b) to the evoked inference (e.g. for the examples below the rocks hurt the cowboys).

1a.

The Indians pushed the rocks off the cliff onto the cowboys.

The cowboys were badly injured

Can rocks be large?

$1 b$.

The Indians pushed the cowboys off the cliff onto the rocks.

The cowboys were badly injured

Can rocks be large?

Sansosti et al. (2013) replicated Saldaña and Frith's (2007) main finding that both typically developed (TD) and ASD readers responded to questions related to an inference more quickly than questions that were unrelated to the inference. In addition, Sansosti et al. (2013) reported that whilst reading the vignettes, the ASD participants had longer average 
reading times, longer average fixation durations and made more fixations and regressions overall, in comparison to the TD group. This finding highlights the discrepancy between offline and online measures of reading. The lack of difference between the groups in response times to the general knowledge questions indicates that the ASD group made bridging inferences online. However, the eye movement data indicate that the online processing of the vignettes was significantly more effortful for ASD participants. Sansosti et al. (2013) interpreted their findings to be consistent with the WCC Theory and suggested that ASD readers access world knowledge online, but have difficulty in the integration of this knowledge into the discourse model. Although possible, this interpretation should be considered tentative, as it is based upon global eye movement measures that are averaged across the reading of the entire vignette. In order to make precise deductions about the exact processes that may differ during reading, both global and localised eye movement measures on critical, experimentally manipulated words and regions of a text are required. Therefore, although this experiment gives evidence for the processing of text to be less efficient in ASD readers, the time course of such differences were not fully explored. Consequently, the aspects of cognitive processing that underpin eye movement differences are unclear.

The second study that used eye tracking to gain an insight into linguistic processing in ASD examined two opposing hypotheses as to why ASD readers have previously been found to perform poorly at the homograph task (Caruana \& Brock, 2014). The homograph task involves participants reading sentences aloud that contain a heterophonic homograph (i.e., a word with one spelling, but two meanings and pronunciations). Readers with ASD are often reported to identify and pronounce the dominant meaning of heterophonic homographs, regardless of sentence context (Happé, 1997; Jolliffe \& Baron-Cohen, 1999; Lopez \& Leekam, 2003; Snowling \& Frith, 1983). Firstly, Caruana and Brock (2014) examined the predominant conclusion drawn from these studies on the basis of the WCC Theory, that an 
impairment in contextual processing is present in ASD. To test this hypothesis, fixation times of students with various levels of self-reported ASD traits were measured (using the Autism Quotient [AQ]; Baron-Cohen, Wheelwright, Skinner, Martin \& Clubley, 2001), on words that were highly predictable by sentence context (e.g. 2a, target word italicised) and words that were unpredictable (e.g. 2b).

2a. Crocodiles live in muddy swamps most of the time.

2b. The girl knows about the swamps in the bush.

For TD readers, a highly constrained context is found to facilitate lexical access, with predictable words being identified more quickly and fixated for less time, than unpredictable words (e.g. Ehrlich \& Rayner, 1981). Caruana and Brock (2014) found students with both high and low AQ scores to show equivalent contextual facilitation, with shorter first fixation durations on the target words when the sentence context was highly constrained (e.g. 2a), in comparison to when it was not (e.g. 2b). This suggests that readers with high AQ scores or 'subclinical levels of ASD' process contextual information at the sentence level, similarly to those with low AQ scores. This contributes to the developing literature that suggests the contextual processing of language to be intact in ASD (e.g. Brock, Norbury, Einav, \& Nation, 2008; Hahn, Snedeker \& Rabagliati, 2015; Hala, et al., 2007; Henderson, Clarke, \& Snowling, 2011; Norbury, 2005) and indicates that the previous reports of poor performance for ASD readers at the homograph task may not be a result of atypical contextual processing (see Brock \& Caruana, 2014; Brock \& Bzishvili, 2013 for a discussion about methodological issues that may have contributed to previous findings of poor performance in the homograph task).

Caruana and Brock (2014) also examined an alternative hypothesis, that poor 
performance on the homograph task may be a result of less efficient comprehension monitoring. In other words, that individual's with ASD do not track comprehension as efficiently as TD readers and therefore may not detect when their interpretation of a sentence is no longer coherent. To examine this hypothesis, participants read sentences that contained a homograph (e.g. crane in 3a below) that was preceded by a determiner and therefore not contextually constrained.

3a. The crane was slowly flying over the lake.

3b. The bird was slowly flying over the lake.

An offline cloze task indicated that for such sentences, participants identified the dominant meaning of the word (e.g. crane - machine), as apposed to the subordinate meaning (e.g. crane-bird). Following the homograph, the sentences contained a disambiguating verb that indicated the dominant meaning of the homograph was incorrect and in fact that the subordinate meaning of the homograph was intended. Typical readers were expected to fixate the disambiguating verb for longer periods when it was preceded by a homograph in comparison to a control synonym (e.g. 3b), as a result of the detection of an initial misidentification of the ambiguous word. This manipulation however did not result in any differences in fixation measures on the disambiguating verb, regardless of AQ score. An interaction was found however, between heterophonic homographs (two pronunciations) and AQ score, but not homophonic homographs (one pronunciation), with participants who had high AQ scores having longer gaze durations (the sum of fixations from when a word is first fixated until the reader leaves that word to either the left or right) on the target, in comparison to those with low AQ scores. This may suggest that participants with high levels of selfreported autistic traits detected the discrepancy for heterophonic homographs, but that those 
with low levels did not. This is in contrast to what was predicted, as it indicates that readers with higher AQ scores were more sensitive to alternations of sentence meaning and therefore were monitoring their comprehension more carefully. Note though, this finding only occurred for a small number of heterophonic homograph stimuli and should therefore be treated with caution. Therefore, Caruana and Brock (2014) did not find support for either hypothesis; contextual processing appeared to be comparable across participants and the findings in relation to comprehension monitoring were unclear. An additional more general observation noted by Caruana and Brock (2014) was that a high AQ score was associated with longer fixations for all sentence and condition types (although only reliable in the predictability experiment). Note that this is similar to what Sanasosti et al. (2013) reported for their sample of clinically diagnosed participants. If it is accepted that findings from a typical population with high levels of self reported autistic traits can be generalised to individuals with a clinical diagnosis, these findings suggest that contextual processing and comprehension monitoring at the single sentence level are intact in ASD.

The third study was conducted by Au-Yeung et al. (2015), who had adult participants with and without ASD read passages of text that contained either a sincere or ironic statement. Previous work that has examined the processing of written irony in a typical population has found ironic statements to require longer processing time and in turn longer fixation times, in comparison to non-ironic statements (Filik \& Moxey, 2010). It was predicted that if readers with ASD are less sensitive to contextual information, as is predicted by the WCC Theory, that the processing of ironic versus sincere utterances would not differ. Alternatively, it was also predicted upon the basis of the CIP Theory, that the comprehension of figurative language is more complex than the comprehension of literal language and therefore readers with ASD should show increased processing disruption when encountering ironic statements, as apposed to sincere statements. Surprisingly however, no differences in 
first pass reading times (the time from when a region of text was initially fixated until that region was left to the left or right) for ironic statements were found between TD and ASD groups, with both displaying longer times for ironic than sincere statements, replicating what has previously been found for a typical population. This suggests that the comprehension of irony was as effortful for TD and ASD readers and is in contrast to both the WCC and CIP Theory. The only group difference detected was that the ASD readers had longer total times (the total amount of time spent fixating a region) for the critical regions in comparison to the TD group. Note that no difference in first pass times were detected and that the increased time that was observed was found for both ironic and sincere texts. The increased total times appeared to be a result of the ASD participants re-reading the passages following initial processing. The authors concluded that this difference was either a result of the ASD readers requiring longer to develop a discourse representation of the text, or that they required longer to conclude that their interpretation of the text was reasonable.

What should be evident from the above studies is that although very few have examined online reading processes in ASD, those that have, focus upon aspects of semantic and discourse processing that are predicted to be impaired by cognitive theories of ASD (e.g. Frith \& Happé, 1994; Minshew \& Goldstein, 1998). However, only two of these studies assessed a clinically diagnosed sample (Au-Yeung et al., 2015; Sansosti et al., 2009) and only one of these demonstrated a difference in the initial extraction of information from the text (Sansosti et al., 2009). Unfortunately this was evident in global reading time measures, which makes the precise cause or timing of this effect difficult to determine. Therefore, the question remains as to how the presence of this developmental disorder impacts upon the online processing of written language.

The aim of the present work was to extend the emerging literature examining online linguistic processing in ASD and to identify whether differences in fundamental lexical, 
syntactic and semantic components of sentence processing are present in individuals with ASD during natural reading. In order to achieve this we adopted robust, benchmark linguistic manipulations from the eye movement and reading literature (Rayner, 1998; 2009).

\section{Experiment 1. Lexical identification in ASD}

Lexical identification refers to the processes a reader engages in to identify a word. There are multiple computational models that specify the exact mechanisms involved in visual word recognition in a typical population and each differ regarding particular aspects of lexical processing (e.g. Coltheart, Rastle, Perry, Langdon \& Ziegler, 2001; Grainger \& Jacobs, 1996; Rumelhart \& McClelland, 1982). For example, the Dual Route Cascaded Model (Coltheart et al., 2001) includes separate lexicons for phonological and orthographic information and the Multiple Read Out Model includes variable response criteria that can be altered dependent upon task requirements (Grainger \& Jacobs, 1996). However, these models are similar at a more basic level, in that they propose words to be identified by a matching process between encoded orthographic information relative to a stored word representation in the mental lexicon (cf. Siedenberg \& McClelland, 1986). Regardless of the precise mechanistic account underpinning lexical identification, in the current experiment, we were interested in whether the time course of such lexical processing is similar in ASD readers.

Performance accuracy for word identification tasks varies between individuals with ASD (e.g. Nation et al., 2006), however, for individuals without language impairment or learning difficulties, performance on word identification tasks is generally found to be intact. For example, children and adolescents with ASD have been found to use both phonological and orthographic decoding strategies when identifying words, be as accurate as TD peers in the reading of words aloud and have intact word comprehension (e.g. Heumer \& Mann, 2010; Minshew et al., 1995; Saldaña, et al., 2009).

There are also reports however, of atypical lexical processing in ASD that may be 
suggestive of a difference in the timecourse of lexical identification. For example, Kamio, Robins, Kelley, Swainson and Fein (2007) found children, adolescents and young adults with ASD to respond as quickly and accurately as TD participants during a lexical decision task, but to lack facilitaion from closley related semantic primes. Note that this is in contrast to findings of normal semantic priming in ASD participants when other paradigms are adopted (e.g. Hala et al., 2007; Lopez \& Leekam, 2003; Kamio \& Toichi, 2000; Toichi \& Kamio, 2001), but this finding may be indicative of a slow in the access to word meaning. Further support for less efficient lexical processing comes from Sansosti et al. (2009) and Caruana and Brock's (2014) experiments that were previously discussed above and have reported participants with ASD to have longer average fixation durations in comparison to TD readers.

In this experiment, we aimed to directly examine the time course of online lexical identification in adults with ASD in order to identify whether the efficiency of such processing is comparable between ASD and TD readers. This is an important question to address, because if online lexical processing is less efficient, this may cascade forward impacting on later aspects of linguistic processing. Thus, prior to examining online higher order linguistic processing, it is necessary to have knowledge of the proficiency of online visual word identification.

We recorded the eye movements of TD and ASD participants as they read sentences that included words manipulated to be either high or low in frequency. Word frequency is one of the most reliable lexical characteristics that affect the speed of lexical identification. Word frequency is a measure of how often a word occurs in the written language. High frequency words (e.g. people) are identified more quickly than low frequency words (e.g. zombie) because they have been previously encountered more often. This difference in identification speed is reflected in fixation durations, with low frequency words being fixated for significantly longer than high frequency words (e.g. Inhoff \& Rayner, 1986; Rayner \& Duffy, 
1986). Connectionist models posit that each time a word is identified, the baseline level of activity for that word increases and consequently, the more quickly a word reaches the activity threshold necessary for identification (e.g. Rumelhart \& McClelland, 1982). Therefore, the frequency effect is thought to reflect a real difference in the time it takes to identify a stored word representation on the basis of visually encoded orthographic information. If lexical processing were less efficient in ASD, we would expect these readers to have longer fixations on target words and possibly even show an increased magnitude of the frequency effect, in comparison to the TD participants.

\section{Method}

\section{Participants}

A group of 19 adults with a formal diagnosis of ASD took part in the experiment, 18 of which had a diagnosis of Asperger's disorder and 1 with high functioning ASD (3 females, aged 18-52 years). Each ASD participant was administered module 4 of ADOS-2 (Lord et al., 2012) and all but four met the autism spectrum cut off criteria. When these participants were excluded the pattern of effects did not change and therefore all participants are included in all analyses reported below. The control group consisted of 18 TD adults (4 females, aged 20-

52). Participants had normal or corrected to normal vision, were native English speakers and did not differ in age $t(35)=0.94, p=.354($ TD $M=28$ years $S D=9$, ASD $M=31$ years $S D$ =10). The ASD group had a significantly higher number of self-reported autistic traits in comparison to the TD group, as measured by the AQ (Baron-Cohen, et al., 2001) $t(32)=$ 9.24, $p<.001(\mathrm{TD} M=15 S D=8$, ASD $M=37 S D=6)$, but did not differ in verbal IQ $t(35)$ $=0.58, p=.621(\mathrm{TD} M=117 S D=11, \mathrm{ASD} M=118 S D=11)$, performance IQ $t(34)=$ $0.99, p=.331(\mathrm{TD} M=112 S D=11, \mathrm{ASD} M=116 S D=15)$ or full scale IQ $t(35)=0.87, p$ $=.389(\mathrm{TD} M=116 S D=11, \operatorname{ASD} M=119 S D=12)$, as measured by the Weschler Abbreviated Scale of Intelligence (Wechsler, 1999). In addition, the two groups did not differ 
in expressive language ability $t(35)=0.53, p=.599(\mathrm{TD} M=88 S D=6$, ASD $M=87 S D=$ 6), as measured by raw scores on the sentence repetition subscale of the Clinical Evaluation of Language Fundamentals II (Semel, Wiig \& Secord, 2003). General reading ability was assessed using raw scores from the York Assessment of Reading Comprehension (Snowling et al., 2010) and performance between groups did not differ for a single word reading task; $t$ (33) $=0.51, p=.614($ TD $M=68 S D=2$, ASD $M=68 S D=3)$ nor for a passage comprehension task; $t(34)=0.35, p=.727(\mathrm{TD} M=9.19 S D=1.77$, ASD $M=8.97 S D=$ 2.03). Participants were paid for their time and either visited the University of Southampton to be tested, or were visited at their homes and completed the experiment in the psychology departments mobile research unit.

\section{Materials}

Thirty-four sentence pairs were developed to include a target word located at approximately the centre of each sentence that was either high (HF e.g. 4a below) or low frequency (LF e.g. 4b). In the examples below the slashes denote region of interest boundaries.

4a. |John walked to the large| office| yesterday morning.|

4b. |John walked to the large| cavern| yesterday morning.|

All target words were six letter nouns and significantly differed in frequency $t(33)=12.95, p$ $<.001(\mathrm{HF} M=151.43 S D=3.04$, LF $M=3.04 S D=10.04)$, but not in the number of orthographic neighbours; $t(33)=0.45, p=.659(\mathrm{HF} M=1.71 S D=2.38, \mathrm{LF} M=1.44 S D=$ 2.67), mean bigram frequency; $t(33)=1.34, p=.190($ HF $M=3896.04 S D=7614.47$, LF $M$ $=3419.44 S D=1353.73)$, number of syllables; $t(33)=0.37, p=.768($ HF $M=1.85 S D=$ 0.56 , LF $M=1.88 S D=0.48)$ or number of morphemes; $t(33)=0.81, p=.422(\mathrm{HF} M=1.21$ 
$S D=0.41, \operatorname{LF} M=1.26 S D=0.45$ ), as obtained from the SUBTLEX database (Brysbaert $\&$ New, 2009). Target words were equally unpredictable $t(33)=1.66, p=.107$ (HF $M=.01 S D$ $=.03$, LF $M=.00 S D=.00$ ), as rated by 12 undergraduate students on a cloze task. In addition, sentences in each condition did not differ in plausibility $t(33)=1.65, p=.109$ (HF $M=4.35 S D=0.49$, LF $M=4.15 S D=0.56$ ) as rated by 13 undergraduate students (who had not taken part in the cloze task) on a five point likert scale as to how likely it was that the events they describe would occur $(1=$ very unlikely, $3=$ quite likely, $5=$ very likely $)$. A full set of the materials can be obtained by contacting the first author.

\section{Procedure}

Participants read sentences presented on a 19-inch LCD computer monitor $(75 \mathrm{~Hz})$ as their head position was stabilised using a forehead and chin rest. The right eye was monitored (viewing was binocular) using an Eyelink 1000 (SR Research) operating at a sampling rate of $1000 \mathrm{~Hz}$. Before the experiment began, a calibration procedure was completed whereby participants fixated three dots on the screen that appeared sequentially on a horizontal line where the sentences were set to appear. Following calibration, a validation procedure was completed to assure fixations were within $0.5^{\circ}$ of each point.

At the start of each trial, participants fixated a dot on the far left of the screen, where the first letter of each sentence was set to appear. If fixation was off-centre, participants were re-calibrated. If calibration was accurate, the experimenter triggered a sentence to appear. Sentences were presented one at a time and participants were instructed to read normally and to press a button on a controller once they had finished reading each sentence. Sentences were presented in random order. Following $50 \%$ of the sentences, participants were asked a simple comprehension question about what they had just read. Participants responded with a "Yes/No" answer using a button controller. Instructions as to which button corresponded to 
each answer were included beneath each question. In total, the eye-tracking task took approximately 25 minutes.

\section{Design}

A 2 X 2 design was employed, with sentence type as a within participants variable (Experiment 1: High vs. Low frequency; Experiment 2: High vs. Low attachment) and group (TD vs. ASD) as a between participants variable. The experimental sentences from Experiment 1 and Experiment 2 (44 sentence pairs manipulated to include an ambiguous prepositional phrase) were presented to participants within the same testing session. All experimental sentences were divided into four separate lists that each contained only one version of each sentence pair. In total each list consisted of 88 sentences; 34 that included a frequency manipulation (17 HF, $17 \mathrm{LF}$ ), 44 manipulated to include an ambiguous prepositional phrase (22 high attached, 22 low attached) and 10 practice sentences that were presented prior to experimental sentences. Each participant read one of the four sentence lists.

\section{Experiment 1: Results}

\section{Data preparation and analysis}

Fixations below $80 \mathrm{~ms}$ and above $800 \mathrm{~ms}$ were removed from analysis, resulting in a loss of less than $1 \%$ of the original fixation data. Trials when a participant blinked whilst fixating the target word and when the trial was disrupted in some way were also removed, resulting in a loss of $7.95 \%$ of data. In addition, data points that were more than 2.5 standard deviations away from the mean (computed individually for each participant per condition) were further excluded. This led to a loss of less than $3 \%$ of data from each fixation measure calculated. Comprehension accuracy was high for both groups (TD $M=0.94, S D=.07$; ASD $M=0.97, S D=0.04)$, which indicates that offline comprehension was not impaired.

For fixation measures, data was log transformed and confirmatory linear mixed effects models (Baayen, Davidson \& Bates, 2008) were computed using the lme4 package 
(Bates, Maechler, Bolker \& Walker, 2014) for R (R Core Team, 2015), with group (TD vs. ASD) and frequency (HF vs. LF) defined as fixed categorical factors. Contrasts to obtain main effects and the associated interaction were coded using the contr.sdif function from the MASS library (Venables \& Ripley, 2002). The full random structure was included (Barr, Levy, Scheepers \& Tily, 2013); with crossed random effects specified for both participants and items. At the participant level, random slopes were included for frequency. At the item level, random slopes were included for frequency, group and the associated interaction between these factors. This resulted in the following syntax; lme(depvar $\sim$ group*frequency + $(1+$ frequency|participants $)+(1+$ group $*$ frequency|items $)$, data $=$ data $).$ Effects were identified as significant if $t>2$.

For binary variables (skipping and regressions), logistic linear effects models were computed. For logistic models, when the full random structure was included (as specified for continuous measures), models would not converge. Models were systematically trimmed of parameters, beginning with the interaction in the random structure, until model convergence was achieved. This resulted in a random structure whereby random slopes were only included for frequency at the participant level, as depicted in the following syntax; glmer(depvar group $*$ frequency $+(1+$ frequency $\mid$ participants $)+(1$ items $)$, data $=$ data, family $=$ binomial $)$. Binary variables were identified as significant when $z>2$.

\section{Global measures}

To examine whether there were any basic sampling differences between the two groups, the mean fixation duration, mean fixation count and total sentence reading time was calculated across each trial. Model parameters and observed means for each of these measures are presented in Table 1 .

No difference between groups was found for mean fixation duration, but an effect of frequency was found, with sentences that included a low frequency word receiving longer 
average fixation durations than those that included a high frequency word. No interaction between group and frequency was detected. For mean fixation count, a reliable difference between groups was found, with ASD readers making more fixations over the course of each trial, in comparison to TD readers. However, the number of fixations participants made over the course of each trial was not affected by the frequency of the target word, and there was no interaction. Total sentence reading times were also found to be significantly longer for the ASD group, in comparison to the TD group, but there was no effect of frequency and no group by frequency interaction.

These global measures indicate that the ASD group extracted information during fixations at a similar speed to TD readers, but made more fixations during the course of each trial and also had longer sentence reading times, in comparison to TD participants.

\section{**INSERT TABLE 1 ABOUT HERE**}

\section{Target analysis}

A region of interest was created around the target noun. For the target word, the following eye movement measures were calculated; skipping, first fixation duration (the duration of the first fixation on the target), single fixation duration (the duration of a fixation on the target, when this was the only fixation made on this word during first pass reading), gaze duration and total time.

All reading measure means and standard deviations for each region of analysis are included in Table 2 and the model parameters are presented in Table 3. Word frequency did not have an affect on the probability of the target word being skipped. However, frequency was found to affect the duration of first fixations, single fixations, gaze durations and total times on the target word, with each of these measures being greater for low frequency words in comparison to high frequency words. No interactions were found for any measure and the 
only group difference detected was that the readers with ASD had longer total times for the target region, in comparison to TD readers.

Based on this analysis, there is no evidence for the hypotheses that lexical processing is less efficient in ASD. However, in order to infer the extent to which our data reflect a null effect of group, as apposed to a Type II error, we computed Bayes factor (Kass \& Raftery, 1995; Rouder, Morey, Speckman \& Province, 2012) for the first fixation LME model on the target word reported above (with a frequency by group interaction), when compared to a denominator model that had the same random structure, but only included frequency as a fixed effect. Bayes factor.is a form of Bayesian analysis whereby one can quantify the relative evidence (probability) for apposing hypotheses, based on the change of prior odds to posterior odds, as a result of the observed data. One of the benefits of this approach is that one can assess evidence in favour of a null hypothesis, which is not possible through more traditional null hypothesis significance tests. A detailed description of this analysis is beyond the scope of this paper, however interested readers are referred to (Kass \& Raftery, 1995; Rouder et al., 2012; Wagenmakers, 2007). Thus, to be clear, we directly compared our original model to one that did not specify group as a predictor. We chose to focus this analysis on the first fixation duration data because this measure is highly influenced by the lexical properties of a word and this measure for this region was the first point that frequency had an effect on fixations for the TD group. A Bayes factor of less than 1 would favour the denominator model and a value above 1 would favour the original model (that included a group by frequency interaction). We computed the Bayes factor in R (R Core Team, 2015) using the BayesFactor package (Morey \& Rouder, 2013) with 100,000 Monte Carlo iterations and with $g$-priors scaled to $r=0.5$ for fixed effects. The Bayes factor for the original model, when compared to the denominator model was 0.045. Based on Jeffrey's (1961) evidence categories for Bayes factor, this provides strong evidence in favour of the denominator model 
that did not include group as a predictor. Moreover, the denominator model is 22 times more likely, based on our data, than the original model. This supports the conclusion that the ASD and TD groups did not appear to differ in the efficiency with which they lexically processed the target words.

Note that the lack of group differences in the early stages of target word processing indicates that the increased number of fixations and increased time spent reading the sentences in the global analyses, is not a result of differences in the early stages of lexical processing. In order to determine the possible cause of these global differences, the spatial and temporal characteristics of the extra fixations ASD participants made are examined in the analysis below.

\section{First pass reading}

In the following analyses, the start and end regions of the sentences were examined, in addition to the target word. The start region included all words prior to the target. The end region included all the words following the target. It is possible that the increased sentence reading times and number of fixations made by the ASD group are a result of longer and more effortful first pass reading. To examine whether such a difference exists, gaze durations for the start and end region, and the proportion of regressions made out of the target and end region during first pass was examined.

Recall that no group differences were present for gaze durations in the target region. Similarly, for both the start and the end region, no effect of group, condition or an interaction was detected. Furthermore, for both the target and end region, there were no differences between groups or frequency in the proportion of regressions made out of these regions during first pass of the sentences. What this suggests is that the initial processing of each region of the sentence did not differ between groups.

\section{Second pass reading}


Given the lack of difference detected between groups during the initial processing of the sentences, it is possible that the increased reading and fixations made by ASD participants occurred during second pass reading, that is, after the participants had read each sentence once in its entirety.

Total second pass reading times were first calculated across the entire sentence (summed total times - summed gaze durations, see Table 1). Readers with ASD were found to have larger second pass reading times for the entire sentence, in comparison to TD readers, but there was no effect of condition or any interaction. To determine whether there was a particular area of sentences that the ASD group were re-reading, second pass reading times were computed for each region individually (total time- gaze duration) and the ASD group were found to have longer second pass reading times for the start and end region of the sentence. However, no effect of frequency or any interactions were detected.

To examine whether the ASD group were making more regressions into either the start or target region, in order to engage in second pass reading, the proportion of trials a regression was made into these regions was examined. No effect of group or word frequency was found for either region. This suggests that there was no reliable difference in the proportion of trials with which the two groups regressed into the start and target regions, but that when the ASD group did make such a regression, they spent longer re-reading each region of the sentences, compared to the TD group.

**INSERT TABLE $2 \& 3$ ABOUT HERE**

\section{Experiment 1: Discussion}

We examined online lexical processing in ASD by measuring participant's eye movements as they read sentences that contained a target word manipulated to be of high or low frequency. The target analyses revealed that both TD and ASD readers showed normal word frequency effects for all target fixation measures. Fixations were significantly longer on 
low frequency words, in comparison to high frequency words. This finding of a normal frequency effect extends our current knowledge in relation to lexical processing in ASD, as it demonstrates that in addition to intact performance accuracy for isolated word identification tasks (e.g. Frith \& Snowling, 1983; Mayes \& Calhoun, 2006; Minshew et al., 1995; Saldaña et al., 2009), that the processes engaged in to identify a word during normal reading appear to be comparable between ASD and TD readers. This is in line with cognitive theories of ASD that suggest low level 'bottom up' processing to be intact (e.g. Minshew \& Goldstein, 1998).

Our findings are inconsistent however with Sansosti et al.'s (2009) study that reported ASD readers to have longer average fixation durations. We found no evidence of such a difference in our data. This inconsistency may be attributable to the differences between the stimuli employed by our own and Sansosti et al.'s (2013) experiment. The vignettes in Sansosti et al.'s (2013) study were designed to evoke a bridging inference, whereas our sentences required no inferences to be made in order to comprehend sentence meaning. Our finding therefore gives indirect support for Sansosti et al.'s (2013) interpretation that the larger average fixation durations observed for ASD participants, reflected more effortful processing in relation to the computation of an inference, as apposed to differences in lexical processing.

In the global analyses, we found participants with ASD to spend longer reading sentences and make more fixations overall, during the course of a trial. This is consistent with what Sansosti et al. (2009) reported, however the time course of the increased reading time found for their experiment was not reported, making the cause of these global effects unclear. In our analysis we examined the time course of the increased reading times for the ASD participants, in order to determine whether these differences were related to our experimental manipulation, and the nature of such increased reading. This analyses revealed no difference between the groups for first pass reading times or first pass regressions, which suggests that 
the speed and manner in which an initial sentence interpretation was constructed to be alike for both TD and ASD participants. Crucially, although our experiments were not designed to examine integrative processes, this finding is inconsistent with theories that suggest such processes to be atypical in ASD (e.g. Frith \& Happé, 1994, Minshew \& Goldstein, 1998). If integration were more effortful for ASD readers, we would have found longer gaze durations in each region and a larger proportion of first pass regressions being made. This was not the case.

The analyses also suggested that the increased sentence reading times for ASD participants appeared to be wholly a result of the these participants re-reading the sentences for significantly longer periods of time than the TD group. Note that this increased re-reading appeared to be unrelated to our target word manipulation, with re-reading occurring equally often for sentences that contained low and high frequency words and is consistent with what Au-Yeung et al. (2015) report for ironic and sincere texts. In addition, no group differences in the proportion of regressions made between groups were found. This is inconsistent with Sansosti et al.'s (2009) finding of increased regressions being made by ASD participants and indicates that our ASD group were as likely as the TD group to make a regression out of a region and also that the target of this regression did not differ. What did differ, was that once having made a regression, the ASD readers spent longer re-reading the sentences.

The cause of this re-reading behaviour is unclear, but it seems unlikely to be a result of a linguistic processing deficit per se, as any difficulty associated with the extraction of sentence or word meaning would have been evident during first pass reading. We speculate that this difference may reflect a 'checking' strategy adopted by the ASD group. Recall that there were comprehension questions after $50 \%$ of sentences and this may have contributed to ASD participants being more cautious of their sentence interpretation and consequently spending longer than TD participants re-reading sentences to ensure that they could answer 
the questions accurately. What is important is that the increased second pass reading was not a result of difficulties in the initial extraction of sentence meaning.

\section{Experiment 2: Syntactic and Semantic Processing}

It is common to encounter structural ambiguities within natural language; however, these often go unnoticed due to the parsing preferences readers hold. For example, in the sentence below (5) the prepositional phrase is syntactically ambiguous.

5. Jane hit the man with the handlebar moustache.

A reader can either attach the prepositional phrase high as a modifier to the verb hit, or low as a modifier to the noun phrase the man. The two possible syntactic structures result in a different sentence interpretation, with the first suggesting that Jane hit the man using a handlebar moustache and the latter suggesting that Jane hit the man who had a handlebar moustache. For sentence 5, if a high attached structure is adopted, the sentence meaning is implausible and reading is disrupted (e.g. Rayner, Carlson \& Frazier, 1983; Taraban \& McClelland, 1988). This is because the reader has to re-evaluate their initial parse of the sentence, to adopt the alternative, low attached structure. This disruption is evident in the eye movement record as increased fixation durations on the disambiguating noun and increased regressions out of this region, to re-read previous parts of the sentence (e.g. Joseph \& Liversedge, 2013; Rayner et al., 1983).

There are several theoretical positions adopted as to why certain structures are preferred and initially adopted by readers. The Garden Path theory (Frazier \& Rayner, 1982) posits that sentences are parsed according to two principles; Minimal Attachment and Late Closure. Minimal Attachment is a rule according to which a reader will always initially build the simplest syntactic structure, and the Late Closure rule stipulates that the parser will always attach a phrase to the currently open phrase structure. An alternative theoretical 
position is that of Constraint-Based models where the language processor is assumed to be interactive and higher order information such as contextual information can influence initial decisions (e.g. MacDonald, Pearlmutter \& Seidenberg, 1994). There are other theoretical accounts of parsing too (e.g. Construal, Frazier \& Clifton, 1996; Race Based Parsing, Van Gompel, Pickering \& Traxler, 2000; Good Enough Parsing, Ferreira, Bailey \& Ferraro, 2002). For present purposes, we will again sidestep the issue of which theoretical account provides the most adequate account of processing, and instead simply accept that processing biases exist for sentences with particular linguistic characteristics. On this basis, in Experiment 2, analogous to Experiment 1, we will investigate how comparable on-line syntactic processing is in TD and ASD readers.

The research that has examined syntactic processing in ASD during spoken language processing has reported mixed results (for a review see Eigsti, Marchena, Schuh \& Kelley, 2011), and little work has been conducted to examine the syntactic processing of written sentences. In a study assessing the impact of ASD and language phenotype on reading comprehension, Lucas and Norbury (2014) had children with ASD and typical language skills (ALN); children with ASD and language impairments (ALI) and TD participants read sentences that were syntactically 'scrambled'. All groups showed equivalent disruption to reading times when reading scrambled sentences, however there was a trend to suggest that the ALI participants took longer to read syntactically legal sentences, in comparison to the TD and ALN participants, who did not differ. This suggests that syntactic processing in ASD may be intact, but that the presence of language impairment has an impact upon the efficiency of syntactic processing during reading (Lucas \& Norbury, 2014). Stockbridge, Happé and White (2014) found that children with ASD were as accurate as TD children in the identification of the indirect object of a verb in sentences that varied in structural form. In addition, both TD children and children with ASD showed higher accuracy for sentences 
containing a preposition phrase construction (e.g. Toby read the book to Jenny) in comparison to a double object construction (e.g. Toby read Jenny the book), indicating that both TD and ASD children benefited from the indirect object being more explicit. These results are consistent with Lucas and Norbury's (2014) finding and suggest that syntactic processing of written sentences is intact in ASD. The important finding from these experiments in relation to the current work is that the individuals with ASD appeared to exhibit comparable syntactic processing to that observed in TD children.

There is evidence, however, of a delay in the detection of syntactic errors in ASD. Koolen, Vissers, Hendriks, Egger and Verhoeven (2012) had adults with ASD take part in a 'single' or 'dual' level reading task where sentences were presented in a serial viewing paradigm. For the dual task participants had to detect orthographic errors (letter substitutions e.g. the dog berks/barks) and syntactic errors (verb agreement errors e.g. she takes the broom and sweep/s the floor), and in the single task participants had to detect only one error type (lexical or syntactic). Koolen et al. (2012) found that ASD and TD participants did not differ in their performance accuracy for either task and that for the single task reaction times did not differ. However, during the dual task, ASD participants were slower to detect both orthographic and syntactic errors, in comparison to the TD group who only showed a slowed response for orthographic errors. The lack of difference between groups for the single task was taken as evidence of intact lexical and syntactic processing in ASD. The slow in the detection of both types of errors under dual task conditions however suggested that when both lexical and syntactic information had to be monitored simultaneously that processing became less efficient. Furthermore, Koolen, Vissers, Egger and Verhoeven (2014) replicated this study but also recorded event related potentials (ERP) and found that when an orthographic error was encountered, both TD and ASD participants emitted comparable P600 (a positive waveform that has previously been associated with error detection) responses 
under both task conditions. However, larger P600 amplitudes were found for ASD readers upon the detection of syntactic errors under both dual and single task conditions. The authors concluded that it is reduced attentional modulation, as apposed to atypical linguistic processing that results in poor performance for reading tasks in ASD and that the increased P600 amplitudes for syntactic errors reflect a difficulty in the processing of language during complex tasks. It is therefore possible that more basic differences in the online processing of information are present in ASD during normal reading conditions, which requires the simultaneous processing of lexical and syntactic information.

From the work mentioned above, it would seem that individuals with ASD are able to accurately complete tasks requiring syntactic processing, however it is unclear whether the efficiency of such processing is similar between ASD and TD groups. A recent study (Riches, Loucas, Baird, Charman \& Simonoff, 2015) had adolescents with ASD complete an aural comprehension task for sentences that contained an ambiguous prepositional phrase (e.g. the girl approached the butterfly on the log). Response times were longer for each group when the picture displayed reflected the least plausible interpretation, suggesting that both groups had to reanalyse their initial plausible interpretation of the sentence, prior to making a response. In addition, participants with ASD had longer response times overall, indicating that they required longer to complete the task in all conditions. However, as noted by the authors, it is unclear whether this increase in response time reflects differences in the efficiency of language processing, or a more task oriented effect, such as increased scanning of the pictures. In addition, there was a trend to suggest that ASD participants may hold a stronger high attachment bias, in comparison to a TD group. However, again, the exact cause of this effect is difficult to pinpoint given the analysis of reaction times. What this experiment does elucidate however is that when presented with visual displays of an image, individuals 
with ASD were able to reanalyse their initial interpretation of a sentence and select an alternative.

In the present study we aimed to further examine the processing of such sentences in ASD, however we were specifically concerned with such processing and its time course during natural reading (as apposed to during listening, and in the absence of visual cues). We had participants with and without ASD read sentences that contained an ambiguous prepositional phrase and were designed to evoke a high attachment preference. We were more specifically interested in whether the syntactic preferences held by ASD participants for ambiguous sentences are similar to those of TD readers and also whether the time course of disruption to reading by an initial syntactic misanalysis was comparable between groups. We predicted that if readers with ASD did not hold a high attachment preference for sentence stimuli, they would not show disruption to reading upon encountering the disambiguating noun in low attached sentences. Alternatively, if readers with ASD do hold a high attachment preference, but are less efficient in the recovery from an initial syntactic misanalysis, we would expect to find increased disruption to reading for low attached sentences, in comparison to the TD group.

The second aim of this experiment was to assess whether ASD readers use world knowledge online during reading. The detection of an incorrect interpretation for low attached sentences is dependent upon a reader's ability to evaluate their sentential interpretation against their knowledge of the world. Therefore, in Experiment 2 we were able to directly assess the efficiency of online world knowledge use during reading.

Impairments in performance accuracy are often found for reading comprehension and inferencing tasks in ASD (Heumer \& Mann, 2010; Minshew et al., 1995; Jolliffe and BaronCohen, 1999) and for each of these tasks, the processing of world knowledge and then the integration of this information into the discourse model is critical (Graesser, Singer, \& 
Trabasso, 1994; McKoon \& Ratcliff, 1992). Furthermore, it has been suggested that top down processing may be atypical in ASD (e.g. Minshew \& Goldstein, 1998) and in the context of reading, this may result in the efficiency with which world knowledge is known to be used online being compromised.

Few studies have directly examined the use of world knowledge during reading in ASD and those that have report mixed results. Saldaña and Frith (2009) had participants read two sentence vignettes intended to produce an inference. Participants were then asked a comprehension question that was or was not related to the inference the vignette was intended to evoke. Reaction times to the questions did not differ between TD and ASD readers and both groups showed faster responses when the question was related to the evoked inference. This was interpreted to suggest that the use of world knowledge is intact in ASD, as ASD participants must have incorporated such information into the discourse model in order to demonstrate an inference priming effect on question reading times. Recall that Sansosti et al. (2013) reported their sample of ASD readers to make longer average fixation durations, more fixations and more regressions on average than their TD group when reading the vignettes originally used in Saldaña and Frith's (2009) experiment. It is therefore possible that subtle differences in the online use of such knowledge are present in ASD and may impact upon the comprehension of larger portions of text, but are undetectable via relatively coarse measures, such as reaction times. Consistent with this hypothesis, Wahlberg and Magliano (2004) found subtle differences between TD and ASD participants in the use of world knowledge to aid recall of ambiguous texts. Participants read passages that were either preceded by a title (informative or non-informative) and with, or without, a primer paragraph that explicitly described the events the stories referred to. Overall, when a cue was present (title or primer paragraph), TD readers recalled more clauses in total and recalled more clauses that demonstrated world knowledge had been integrated into the discourse model, in comparison 
to the ASD group. Note however that the number of clauses recalled that were inferred on the basis of world knowledge did not differ between groups. This suggests that readers with ASD accessed world knowledge online during reading, however they did not use this information as efficiently as TD readers to assist in the disambiguation and recall of the ambiguous texts. This is similar to the conclusions of Sansosti et al. (2013).

In Experiment 2, we aimed to directly examine the time course and efficiency of world knowledge use during reading of syntactically ambiguous sentences in ASD. We predict that if participants with ASD are less efficient in the use of world knowledge during reading, then there will be a delay in their detection of an initial misanalysis of low attached sentences, in comparison to TD readers.

\section{Method}

Participants, procedure and experimental design were identical to Experiment 1.

\section{Materials}

Forty-four sentence frames were devised that included a prepositional phrase that could either be attached high (HA) to a verb (e.g. 6a) or low (LA) to the noun phrase that immediately preceded the preposition (e.g. 6b). Both sentence types were identical aside from the disambiguating target noun.

6a. |Charlie| demolished| the dilapidated house| with| a huge| crane| last| year.|

6b. |Charlie| demolished| the dilapidated house| with| a huge| fence| last| year.|

To confirm that the chosen verbs elicited a high attachment preference in a typical population, 13 undergraduate students completed a cloze task and the experimenter went through each sentence completion with each student, to clarify any possible ambiguities. The students completed the sentences using a noun that resulted in a high-attached structure, $98 \%$ 
of the time. On average, the target words did not differ in length $t(43)=0.17, p=.868$ (HA $M=5.59 S D=1.69$, LA $M=5.57 S D=1.59)$, frequency $t(43)=0.64, p=.524($ HA $M=$ 22.61 $S D=39.20$, LA $M=27.83 S D=61.08)$, number of orthographic neighbours $t(43)=$ $1.25, p=.225(\mathrm{HA} M=4.66 S D=5.55$, LA $M=5.89 S D=6.53)$, mean bigram frequency $t$ $(43)=1.34, p=.186($ HA $M=3587.87 S D=1395.70$, LA $M=4232.46 S D=2079.95)$, number of morphemes $t(43)=0.38, p=.767$ (HA $M=1.25 S D=0.53$, LA $M=1.23 S D=$ $0.48)$ or number of syllables $t(43)=0.83, p=.412($ HA $M=1.59 S D=0.76$, LA $M=1.52$ $S D=0.73$ ), as retrieved from the SUBTLEX database (Brysbaert \& New, 2009). To assure the high and low attached sentences did not differ in plausibility, 15 undergraduates (who had not completed the cloze task) rated how likely it was that the events described in the sentences would occur on a 5 point likert scale $(1=$ extremely unlikely, $3=$ quite likely, $5=$ extremely likely). To avoid the low attachment of the prepositional phrase acting as a confounding variable that may cause participants to rate these sentences as less likely, the sentences rated were an unambiguous description of the events depicted in the sentences (e.g. see $7 \mathrm{a}$ and $7 \mathrm{~b})$.

How likely is it...

7a. that a crane would be used to demolish a huge, dilapidated house.

7b. that a huge, dilapidated house that has a fence, would be demolished.

The order of items was pseudo-randomised so that the same sentence versions (e.g. 7a \& b) were at least 20 items apart. Participant ratings indicated that the events described in the sentences did not differ in plausibility $t(43)=1.30, p=.200($ HA $M=3.39 S D=0.78$, LA $M$ $=3.27 S D=0.79$ ). A full set of materials can be obtained by contacting the first author. 


\section{Data preparation}

Sentences were divided into eight regions, three of which were of primary interest; the pre-target region which consisted of a determiner and adjective that immediately followed the preposition; the target, which consisted of the disambiguating noun and the post target region which included the one or two words that followed the target (e.g. 6a \& b).

Data exclusion procedures where the same as Experiment 1, which resulted a loss of $4.74 \%$ of the original data, and a loss of less than $3 \%$ of data from each fixation measure analysed. Sentence comprehension was high for both participant groups and therefore, similarly to what we found for Experiment 1, any differences detected in the eye movement data did not appear to impact upon offline comprehension outcomes (TD $M=.96 S D=.04$; ASD $M=.97 S D=.05$ ). Analyses procedures were also identical to Experiment 1, but with each model containing attachment condition (HA vs. LA) in place of frequency.

\section{Global measures}

Global measures were calculated across trials to identify whether there were any basic sampling differences between TD and ASD readers during the reading of the syntactically ambiguous sentences. Means, standard deviations and model parameters for the global analysis are displayed in Table 4. No differences between groups or sentence types were detected for mean fixation duration and there was no interaction. For mean fixation count, there was a significant effect of attachment, with both groups making more fixations when sentences were low attached, in comparison to high attached. In addition, there was a significant effect of group, with ASD readers making more fixations overall in comparison to TD readers, but there was no interaction. A similar pattern was also found for sentence reading time, with both groups having longer reading times for low attached sentences, in comparison to high attached sentences, and ASD readers having longer reading times overall, 
but again there was no interaction. These findings replicate what was found for Experiment 1 and are explored in more detail later.

\section{**INSERT TABLE 4 ABOUT HERE**}

\section{Pre-target region}

Means, standard deviations and model parameters for all region analyses are displayed in Tables 5, 6 and 7. Note that the pre-target region was identical across both high and low attached sentences and as a result, no effect of attachment was found for skipping, first fixation durations, single fixation durations, gaze durations, go past times (the time from when a word is first fixated until the eyes leave this region to the right, including all time spent re-reading previous regions of the sentence) or the proportion of regressions made out of this region. In addition, group membership did not have an effect on any of these measures, and there were no interactions. An effect of both attachment and group was found, however, for total times, with the ASD group fixating this region for longer than the TD group overall and both groups spending longer fixating this region when the sentence was low attached. In addition, an effect of attachment for the proportion of regressions made into the pre-target region was found, with both groups regressing back into the pre-target region on a higher proportion of trials when the prepositional phrase was low attached, in comparison to when it was high attached. No group difference or interaction was detected.

\section{**INSERT TABLES 5, 6 AND 7 ABOUT HERE**}

\section{Target region}

The target word disambiguated the prepositional phrase attachment and was therefore the point at which participants were expected to first show disruption to reading for low attached sentences. One unexpected finding was that ASD readers were less likely to skip the target region in comparison to TD readers, but this did not differ between attachment conditions and there was no interaction. No effect of group or attachment was found for first 
fixations durations, indicating that during the very early stages of target processing, neither TD nor ASD readers had detected an incorrect interpretation. An effect of attachment was first present in single fixation durations, with both groups spending longer fixating target words in low attached sentences, in comparison to high attached sentences. No group differences or interactions were detected, indicating that the onset and severity of initial processing disruption was equivalent for TD and ASD readers. Similarly, gaze durations and go past times were found to be longer for target words within low attached sentences. Again, no group differences or interactions were found for these measures. Expectedly, an effect of attachment was also present in total times, with longer time being spent fixating target words for low attached sentences in comparison to high attached sentences, but no group difference or interaction was present. In addition, both groups made a higher proportion of regressive fixations into the target region when the sentence was low attached, in comparison to high attached, but the proportion of first pass regressions made out of the target region did not differ between groups or attachment conditions.

The results above provide no evidence for the hypothesis that readers with ASD may display increased disruption for low attached sentences, or a delay in the onset of disruption, in comparison to TD readers. In order to examine the supportive evidence for this null effect, we again compared the single fixation duration LME reported above to a denominator model that only included prepositional phrase attachment as a fixed effect using Bayes factor. We were, therefore, once again able to directly compare the relative evidence for the original model to a model that excludes group as a predictor. We analysed the single fixation duration data because this was the first point in time an effect of prepositional phrase attachment was detected for the TD group, and this is a critical measure in relation to our hypotheses, where differences in the magnitude or onset of the effect might be expected to occur. A Bayes factor of 0.037 was computed using the same methods as detailed in Experiment 1 . This indicates 
that there is strong evidence that the denominator model is more probable and is 27 times more likely based on the observed data, than the original model that included a group by prepositional phrase attachment interaction. Our analysis provides evidence in favour of a null effect of group in our data during the initial processing of the target word.

\section{Post target region}

The post target region was examined to assess the extent to which low attached sentences continued to disrupt reading, following processing of the target noun. No spillover effects were found, with no effect of group, attachment or any interactions for skipping, first fixations, single fixations or gaze durations. Attachment did however influence go past times, with both groups taking longer to progress to the right, past the post target region, when the sentences were low attached, in comparison to high attached sentences. In addition, there was a difference between groups, with ASD participants having longer go past times overall for this region, but this did not interact with condition. For total times, there was a main effect of attachment and group, with all participants spending longer fixating this region for low attached sentences and the ASD group spending longer in this region overall. Participants made significantly more regressions out of the post target region when the sentences were low attached and this did not differ or interact with group. There were no differences between groups or sentence types in the proportion of regressions made into this region.

\section{First Pass Reading}

To examine whether the increased sentence reading time and number of fixations made by ASD participants in Experiment 2 was a consequence of increased first pass or second pass reading times, additional first and second pass measures were examined. Recall from the main analyses, there were no group differences or interactions in gaze durations for the pre-target, target or post-target region. This was also true for the start, verb, noun, preposition and end regions. Furthermore, there was no effect of attachment and no 
interactions. The probability of readers making a regression out of each region during first pass reading was also examined. If ASD readers made more regressions during first pass this may have contributed to the increased sentence reading times. Recall that in the main analysis, no group differences or interactions were detected in the pre-target, target or post target regions. Similarly, there were no reliable differences between the proportion of first pass regressions made between groups for any other region and there was also no effect of attachment. These analyses suggest that there were no differences in the way the two groups sampled information during first pass reading.

\section{Second Pass Reading}

Analysis of second pass reading time for the entire sentence (see Table 4) indicated that the ASD group had longer second pass reading times overall, in comparison to the TD group and that both groups engaged in more re-reading for low attached sentences in comparison to high-attached sentences. To determine whether this increase in second pass reading of the sentences was a result of the ASD group re-reading a particular area of the sentence, second pass times were calculated for each region. The ASD group had longer second pass times in comparison to the TD group for the start, noun, pre-target, target and end. No differences between second pass reading of the preposition, post target or verb regions were detected, but there is a numerical trend in the data, consistent with the above findings. In addition, a reliable effect of attachment was detected for the noun and pre-target region, indicating that when sentences were low attached, both groups re-read these areas of the sentence more so, to assist in structural reanalysis. No interactions or effects of attachment were detected for any other region. Recall from the main analysis that both groups made a higher proportion of regressions into the target and pre-target regions, when the sentences were low attached. This was also true for the noun and preposition, indicating that this information was crucial for both groups, when reanalysing an initial structural 
interpretation. These findings replicate the findings from Experiment 1, with ASD readers spending significantly longer re-reading each region of the sentence, regardless of sentence condition. Once again this demonstrates that this increased re-reading is independent of our sentence manipulation.

\section{Experiment 2: Discussion}

We examined aspects of syntactic and semantic processing by having participants read sentences that contained an ambiguous prepositional phrase. Our first research question was related to whether readers with ASD hold similar syntactic preferences to TD readers. Both TD and ASD readers displayed disruption to reading for low attached sentences upon fixation of the target word, which indicates that similarly to TD readers, adult readers with ASD hold a high attachment preference. Furthermore, the severity of this disruption did not differ between groups, which suggests that readers with ASD are also as efficient as TD readers, in the recovery from an initial structural misanalysis. These findings suggest that the syntactic parsing of written sentences is intact in ASD.

Our results are consistent with Lucas and Norbury's (2014) study that demonstrated children with ASD to show similar disruption to TD children when reading syntactically scrambled sentences. In addition, similarly to Riches et al.'s (2015) study we found adult readers with ASD to be successful in the reanalysis of an initial interpretation of a sentence containing an ambiguous prepositional phrase. Note however there was no evidence that adults with ASD show a stronger high attachment preference, as a trend in Riches et al.'s (2015) data suggested. Our findings are inconsistent with Koolen et al.'s (2012; 2014) work that suggested syntactic processing to be less efficient in ASD. This inconsistency may be attributable to the difference in task types adopted in our own and Koolen et al.'s (2012; 2014) experiments. The current study simply required participants to read sentences for comprehension, whereas Koolen et al.'s $(2012 ; 2014)$ studies required readers to detect and 
respond to lexical and syntactic errors during a serial viewing paradigm. This requires additional memory load and decisional processes that are not necessary during natural reading.

Our second research question was related to the use of world knowledge online during reading. We predicted that if such processing was less efficient that there would be a delay in the onset of reading disruption for the target word for low attached sentences. However, no such delay was detected, with both groups first showing disruption in single fixation durations. What this suggests, is that counter to our hypothesis and to theories that predict top down, higher order processing to be atypical (e.g. Minshew \& Goldstein, 1998), ASD readers had access to and made use of world knowledge online and did so as efficiently as TD readers. This finding is consistent with Saldaña \& Frith's (2009) study that reported participants with ASD to use world knowledge in order to make an inference, and in turn respond more quickly to comprehension questions that were related to such an inference. However, our finding is inconsistent with Wahlberg and Magliano's (2006) report of ASD readers being less efficient in the use of world knowledge. Note that Wahlberg and Magliano's (2006) study examined the use of such knowledge to aid in the recall of ambiguous texts and it is therefore possible that the difference reported by Wahlberg and Magliano (2006) is specifically related to memory functions following text comprehension, as apposed to linguistic processing per se.

There were two subtle differences found between the participant groups in the early processing of the sentences examined for Experiment 2. Firstly, the ASD readers were less likely to skip the target word of both high and low attached sentences, in comparison to TD readers. The lack of difference in skipping found in Experiment 1 and all other critical regions of the sentences in Experiment 2, suggests that the lower rate of skipping was not a result of an inherent difference in skipping probabilities in ASD, but is localised to this 
region. Decreased skipping of the target word in the ASD group may reflect the adoption of a more cautious reading strategy. It is possible that this is a result of the ASD readers being sensitive to the manipulation of attachment and consequently the importance of the disambiguating target noun. Therefore, decreased skipping may have been a strategy adopted in order to avoid overlooking a potential misanalysis.

The second group difference was that ASD readers were found to have longer go past times for the post-target region. Since this was present across both high and low attachment conditions. If this was evidence of increased disruption for low attached sentences for readers with ASD, we would have found an interaction whereby go past times were larger for ASD readers for low attached sentences only. However, this is not the case and thus it is likely a consequence of the increased re-reading that ASD participants engaged in for all sentences (note that the post target region was often the penultimate word in the sentence).

Differences in the later stages of sentence processing were also detected. Replicating what was found for Experiment 1, no group differences or interactions for first pass reading were found. What this suggests is that the ASD readers did not differ from the TD group in the speed with which they constructed an initial interpretation of the sentence. The ASD group did differ however in the amount of second pass reading they engaged in, following intact initial processing. Again this increased re-reading was found across both sentence types and was unrelated to the sentence manipulation. As for Experiment 1, we speculate that this may be a strategy adopted by the participants with ASD to 'check' their understanding of the sentence, prior to (possibly) answering a comprehension question. Different reading strategies have been previously identified in a TD population (Hyönä, Lorch \& Kaakinen, 2002) and it is therefore possible that the increased re-reading and reduced skipping for the target region may be part of a more general, cautious reading strategy, adopted by ASD participants. 
Finally, in relation to what would be expected in terms of typical cognitive processing from general theories of reading, the overall findings from the two experiments for TD readers replicate previous findings. In ASD readers however, this was not the case. Here, the findings replicate those that would be predicted for normal cognitive processing in first pass measures, but for second pass reading there was evidence for atypical cognitive processing which is not in line with any general theory of reading.

\section{Conclusion}

We aimed to gain a more accurate understanding as to how lexical, syntactic and semantic processing occurs in adults with ASD during natural reading, by measuring eye movements as participants read single sentences. Overall, there were striking similarities in first pass reading of sentences between TD and ASD readers. Experiment 1 indicated that lexical processing is intact in ASD, with both groups showing a comparable frequency effect. Experiment 2 indicated that there is no difference in syntactic preferences between the groups of readers, and in their ability to detect and recover from an initial syntactic misanalysis through the use of world knowledge. This was demonstrated by the immediacy with which an initial syntactic misanalysis was detected and the magnitude of disruption to reading being comparable between TD and ASD readers. More critically, what these findings imply, is that an impairment in lexical identification, syntactic parsing or the use of to world knowledge during the processing of single sentences is unlikely to contribute to the offline performance differences for reading comprehension and inferencing tasks that have been reported in the literature. The only group differences that were present in the current study appear to be independent of the linguistic manipulations in our experimental sentences and, instead, reflect a more cautious reading strategy that the ASD readers show a preference to adopt. 


\section{References}

American Psychiatric Association. (2013). Diagnostic and statistical manual of mental disorders (5th ed.). Arlington, VA: American Psychiatric Publishing.

Asberg, J., Kopp, S., Berg-Kelly, K., \& Gillberg, C. (2010). Reading comprehension, word decoding and spelling in girls with autism spectrum disorders (ASD) or attentiondeficit/hyperactivity disorder (AD/HD): performance and predictors. International Journal of Language \& Communication Disorders, 45(1), 61-71. doi: $10.3109 / 13682820902745438$.

Au-Yeung, S. K., Kaakinen, J. K., Liversedge, S. P. \& Benson, V. (2015). Processing of Written Irony in Autism Spectrum Disorder: An Eye-Movement Study. Autism Research. doi: 10.1002/aur.1490

Baayen, R. H., Davidson, D. G., \& Bates, D. M. (2008). Mixed-effects modeling with crossed random effects for subjects and items. Journal of Memory and Language, 59, 390412.

Baron-Cohen, S., Wheelwright, S., Skinner, R., Martin, J., \& Clubley, E. (2001). The Autism-Spectrum Quotient (AQ): Evidence from Asperger syndrome/highfunctioning autism, males and females, scientists and mathematicians. Journal of Autism and Developmental Disorders, 31(1), 5-17. doi: 10.1023/a:1005653411471

Barr, D. J., Levy, R., Scheepers, C., \& Tily, H. J. (2013). Random effects structure for confirmatory hypothesis testing: Keep it maximal. Journal of Memory and Language, 68(3), 255-278. doi:10.1016/j.jml.2012.11.001

Bates D, Maechler M, Bolker B and Walker S (2014). lme4: Linear mixed-effects models using Eigen and S4. R package version 1.1-7, http://CRAN.Rproject.org/package $=1 m e 4$. 
Brock, J. \& Caruana, N. (2014). Reading for sound and reading for meaning in autism: Frith and Snowling (1983) revisited. In Arciuli, J. \& Brock, J (Eds.), Communication in Autism (125-145). Amsterdam: John Benjamins Publishing Co.

Brock, J., \& Bzishvili, S. (2013). Deconstructing Frith and Snowling's homograph-reading task: Implications for autism spectrum disorders. The Quarterly Journal of Experimental Psychology, 66(9), 1764-1773. doi:10.1080/17470218.2013.766221

Brock, J., Norbury, C., Einav, S., \& Nation, K. (2008). Do individuals with autism process words in context? Evidence from language-mediated eye-movements. Cognition, 108(3), 896-904. doi: 10.1016/j.cognition.2008.06.007.

Brysbaert, M., \& New, B. (2009). Moving beyond Kucera and Francis: A critical evaluation of current word frequency norms and the introduction of a new and improved word frequency measure for American English. Behavior Research Measures, 41 (4), 977 990. doi: 10.3758/BRM.41.4.977

Caruana, N., \& Brock, B. (2014). No association between autisitic traits and contextual influences on eye-movements during reading. PeerJ, 2:e446.

Coltheart, M., Rastle, K., Perry, C., Langdon, R., \& Ziegler, J. (2001). DRC: a dual route cascaded model of visual word recognition and reading aloud. Psychological Review, 108(1), 204.

Ehrlich, S. F., \& Rayner, K. (1981). Contextual effects on word perception and eye movements during reading. Journal of Verbal Learning and Verbal Behavior, 20(6), 641-655.

Eigsti, I. M., de Marchena, A. B., Schuh, J. M., \& Kelley, E. (2011). Language acquisition in autism spectrum disorders: A developmental review. Research in Autism Spectrum Disorders, 5(2), 681-691. doi:10.1016/j.rasd.2010.09.001 
Ferreira, F., Bailey, K. G., \& Ferraro, V. (2002). Good-enough representations in language comprehension. Current directions in psychological science, 11(1), 11-15.

Filik, R., \& Moxey, L. M. (2010). The on-line processing of written irony. Cognition, 116(3), 421-436. doi:10.1016/j.cognition.2010.06.005

Frazier, L., \& Clifton, C. (1996). Construal. MIT Press.

Frazier, L., \& Rayner, K. (1982). Making and correcting errors during sentence comprehension: Eye movements in the analysis of structurally ambiguous sentences. Cognitive Psychology, 14(2), 178-210. doi: 10.1016/0010-0285(82)90008-1.

Frith, U. (1989). Autism: Explaining the Enigma. Oxford, UK: Basil Blackwell.

Frith, U., \& Happé, F. (1994). Autism - Beyond the theory of mind. Cognition, 50(1-3), 115132.

Frith, U., \& Snowling, M. (1983). Reading for meaning and reading for sound in autistic and dyslexic children. British Journal of Developmental Psychology, 1, 329-342.

Graesser, A. C., Singer, M., \& Trabasso, T. (1994). Constructing inferences during narrative text comprehension. Psychological Review, 101(3), 371-395.

Grainger, J., \& Jacobs, A. M. (1996). Orthographic processing in visual word recognition: a multiple read-out model. Psychological review, 103(3), 518.

Hahn, N., Snedeker, J., \& Rabagliati, H. (2015). Rapid linguistic ambiguity resolution in young children with autism spectrum disorder: Eye tracking evidence for the limits of weak central coherence. Autism Research. doi: 10.1002/aur.1487

Hala, S., Pexman, P. M., \& Glenwright, M. (2007). Priming the meaning of homographs in typically developing children and children with autism. Journal of Autism and Developmental disorders, 37(2), 329-340. doi: 10.1007/s10803-006-0162-6 
Happé, F. G. E. (1997). Central coherence and theory of mind in autism: Reading homographs in context. British Journal of Developmental Psychology, 15, 1-12. doi: 10.1111/j.2044-835X.1997.tb00721.x

Happé, F., \& Frith, U. (2006). The weak coherence account: detail-focused cognitive style in autism spectrum disorders. Journal of Autism and Developmental Disorders, 36(1), 525. doi: 10.1007/s 10803-005-0039-0.

Henderson, L. M., Clarke, P. J., \& Snowling, M. J. (2011). Accessing and selecting word meaning in autism spectrum disorder. Journal of Child Psychology and Psychiatry, 52(9), 964-973. doi: 10.1111/j.1469-7610.2011.02393.x

Huemer, S. V., \& Mann, V. (2010). A comprehensive profile of decoding and comprehension in autism spectrum disorders. Journal of Autism and Developmental Disorders, 40(4), 485-493. Doi: 10.1007/s10803-009-0892-3.

Hyönä, J., Lorch Jr, R. F., \& Kaakinen, J. K. (2002). Individual differences in reading to summarize expository text: Evidence from eye fixation patterns. Journal of Educational Psychology, 94(1), 44-55. DOI: 10.1037//0022-0663.94.1.44

Inhoff, A. W., \& Rayner, K. (1986). Parafoveal word processing during eye fixations in reading: Effects of word frequency. Perception \& Psychophysics, 40(6), 431-439.

Jeffreys, H. (1961). Theory of probability (3rd ed.). New York: Oxford University Press. Jolliffe, T., \& Baron-Cohen, S. (1999). A test of central coherence theory: linguistic processing in high-functioning adults with autism or Asperger syndrome: is local coherence impaired? Cognition, 71(2), 149-185.

Jolliffe, T., \& Baron-Cohen, S. (2000). Linguistic processing in high-functioning adults with autism or Asperger's syndrome. Is global coherence impaired? Psychological Medicine, 30(5), 1169-1187. 
Jones, C. R. G., Happé, F., Golden, H., Marsden, A. J. S., Tregay, J., Simonoff, E., . . . Charman, T. (2009). Reading and Arithmetic in Adolescents With Autism Spectrum Disorders: Peaks and Dips in Attainment. Neuropsychology, 23(6), 718-728. doi: 10.1037/a0016360.

Joseph, H. S. S. L., \& Liversedge, S. P. (2013). Children's and adults' on-line processing of syntactically ambiguous sentences during reading. PloS one, 8(1), e54141.

Kamio, Y., \& Toichi, M. (2000). Dual access to semantics in autism: Is pictorial access superior to verbal access?. Journal of Child Psychology and Psychiatry, 41(07), 859867. doi:http://dx.doi.org/

Kamio, Y., Robins, D., Kelley, E., Swainson, B., \& Fein, D. (2007). Atypical lexical/semantic processing in high-functioning autism spectrum disorders without early language delay. Journal of Autism and Developmental Disorders, 37(6), 11161122. doi: 10.1007/s10803-006-0254-3. doi:10.1016/j.clinph.2013.06.021

Kass, R. E., \& Raftery, A. E. (1995). Bayes factors. Journal of the American Statistical Association, 90(430), 773-795.

Koolen, S., Vissers, C. T. W., Egger, J. I. M., \& Verhoeven, L. (2014). Monitoring in language perception in high-functioning adults with autism spectrum disorder: Evidence from event-related potentials. Clinical Neurophysiology, 125(1), 108-123.

Koolen, S., Vissers, C. T. W., Hendriks, A. W., Egger, J. I., \& Verhoeven, L. (2012). The interplay between attentional strategies and language processing in high-functioning adults with autism spectrum disorder. Journal of Autism and Developmental Disorders, 42(5), 805-814. doi:10.1007/s10803-011-1310-1

Lopez, B., \& Leekam, S. R. (2003). Do children with autism fail to process information in context? Journal of Child Psychology and Psychiatry and Allied Disciplines, 44(2), 285-300. doi:10.1111/1469-7610.00121 
Lord C., Rutter M., DiLavore P. C., Risi S., Gotham K., Bishop S. (2012). Autism diagnostic observation schedule, second edition. Torrance, CA: Western Psychological Services.

Lucas, R., \& Norbury, C. F. (2014). Levels of text compehension in children with autism spectrum disorders (ASD): The influence of language phenotype. Journal of Auitsm and Developmental Disorders, 44, 2756-2768. doi:10.1007/s10803-014-2133-7

MacDonald, M.C., Pearlmutter, N.J., \& Seidenberg, M.S. (1994). The lexical nature of syntactic ambiguity resolution. Psychological Review, 101, 676-703.

Mayes, S. D., \& Calhoun, S. L. (2006). Frequency of reading, math, and writing disabilities in children with clinical disorders. Learning and Individual Differences, 16(2), 145157. doi: 10.1016/j.lindif.2005.07.004

McKoon, G., \& Ratcliff, R. (1992). Inference during reading. Psychological Review, 99(3), 440-466.

Minshew, N. J., \& Goldstein, G. (1998). Autism as a disorder of complex information processing. Mental Retardation and Developmental Disabilities Research Reviews, 4(2), 129-136.

Minshew, N. J., Goldstein, G., \& Siegel, D. J. (1995). Speech and language in highfunctioning autistic individuals. Neuropsychology, 9(2), 255-261.

Minshew, N. J., Goldstein, G., \& Siegel, D. J. (1997). Neuropsychologic functioning in autism: profile of a complex information processing disorder. Journal of the International Neuropsychological Society : JINS, 3(4), 303-316.

Minshew, N. J., Williams, D. L., \& McFadden, K. (2008). Information Processing, Neural Connectivity, and Neuronal Organization. In A. W. Zimmerman (Ed.), Autism: Current Theories and Evidence (pp. 381-405). 
Nation, K., Clarke, P., Wright, B., \& Williams, C. (2006). Patterns of reading ability in children with autism spectrum disorder. Journal of Autism and Developmental Disorders, 36(7), 911-919. doi:10.1007/s10803-006-0130-1

Norbury, C. F. (2005). Barking up the wrong tree? Lexical ambiguity resolution in children with language impairments and autistic spectrum disorders. Journal of Experimental Child Psychology, 90(2), 142-171. doi:10.1016/j.jecp.2004.11.003

R Core Team (2015). R: A language and environment for statistical computing. R Foundation for Statistical Computing, Vienna, Austria. URL https://www.R-project.org/.

Rayner, K. (1998). Eye movements in reading and information processing: 20 years of research. Psychological Bulletin, 124(3), 372. doi: org/10.1037/0033-2909.124.3.372.

Rayner, K. (2009). Eye movements and attention in reading, scene perception, and visual search. Quarterly Journal of Experimental Psychology, 62(8), 1457-1506. doi:10.1080/17470210902816461

Rayner, K., \& Duffy, S. A. (1986). Lexical complexity and fixation rimes in reading - Effects of word frequency, verb complexity, and lexical ambiguity. Memory \& Cognition, 14 (3), 191-201. doi:10.3758/bf03197692

Rayner, K., Carlson, M., \& Frazier, L. (1983). The interaction of syntax and semantics during sentence processing: Eye movements in the analysis of semantically biased sentences. Journal of Verbal Learning and Verbal Behavior, 22, 358-374.

Riches, N. G., Loucas, T., Baird, G., Charman, T., \& Simonoff, E. (2015). Elephants in Pyjamas: Testing the Weak Central Coherence Account of Autism Spectrum Disorders Using a Syntactic Disambiguation Task. Journal of Autism and Developmental Disorders, 1-9. doi:10. 1007/ s10803-015-2560-0

Rouder, J. N., Morey, R. D., Speckman, P. L., \& Province, J. M. (2012). Default Bayes factors for ANOVA designs. Journal of Mathematical Psychology, 56, 365-374. 
doi:10.1016/j.jmp.2012.08.001

Rumelhart, D. E., \& McClelland, J. L. (1982). An interactive activation model of context effects in letter perception: II. The contextual enhancement effect and some tests and extensions of the model. Psychological Review, 89(1), 60.

Saldaña, D., \& Frith, U. (2007). Do readers with autism make briging inferences from world knowledge? Journal of Experimental Child Psychology, 96, 310-319. doi:10.1016/j.jecp.2006.11.002.

Saldaña, D., Carreiras, M., \& Frith, U. (2009). Orthographic and Phonological Pathways in Hyperlexic Readers With Autism Spectrum Disorders. Developmental Neuropsychology, 34(3), 240-253. doi:10.1080/87565640902805701

Sansosti, F. J., Was, C., Rawson, K. A., \& Remaklus, B. L. (2013). Eye movements during processing of text requiring bridging inferences in adolescents with higher functioning autism spectrum disorders: A preliminary investigation. Research in Autism Spectrum Disorders, 7(12), 1535-1542. doi:10.1016/j.rasd.2013.09.001

Seidenberg, M. S., \& McClelland, J. L. (1989). A distributed, developmental model of word recognition and naming. Psychological Review, 96(4), 523.

Semel, E., Wiig, E. H., \& Secord, W. A. (2003). Clinical evaluation of language fundamentals, fourth edition (CELF-4). Toronto, Canada: The Psychological Corporation/A Harcourt Assessment Company.

Snowling, M.J., Stothard, S.E., Clarke, P., Bowyer-Crane, C., Harrington, A., Truelove, E., Nation, K. \& Hulme, C. (2010). York Assessment of Reading for Comprehension: Passage Reading - Secondary Version. GL Assessment.

Stockbridge, M. D., Happé, F. G. E., \& White, S. J. (2014). Impaired comprehension of altering syntactic constructions in autism. Autism Research, 7, 314-321. 
Taraban, R., \& McClelland, J. L. (1988). Constituent attachment and thematic role assignment in sentence processing: Influences of content based expectations. Journal of Memory and Language, 27(6), 597-632. doi:10.1016/0749-596x(88)90011-3

Toichi, M., \& Kamio, Y. (2001). Verbal association for simple common words in highfunctioning autism. Journal of Autism and Developmental Disorders, 31(5), 483-490. doi: 10.1023/A:1012216925216

Van Gompel, R. P., Pickering, M. J., \& Traxler, M. J. (2000). Unrestricted race: A new model of syntactic ambiguity resolution. Reading as a perceptual process, 621-648.

Venables, W. N. \& Ripley, B. D. (2002) Modern Applied Statistics with S. Fourth Edition. Springer, New York. ISBN 0-387-95457-0

Wagenmakers, E. (2007). A practical solution to the pervasive problems of $p$ values. Psychonomic Bulletin \& Review, 14(5), 779-804.

Williams, Diane, L., Goldstein, G., \& Minshew, N. J. (2006). Neuropsychologic functioning in children with autism: Further evidence for disordered complex informationprocessing. Child Neuropsychology, 12, 279-298. Doi: 10.1080/09297040600681190

Wahlberg, T., \& Magliano, J. P. (2004). The ability of high function individuals with autism to comprehend written discourse. Discourse Processes, 38(1), 119-144. doi:10.1207/s15326950dp3801_5

Wechsler, D. (1999). Wechsler Abbreviated Scale of Intelligence. The Psychological Corporation: Harcourt Brace \& Company. New York, NY. 
Table 1.

Model parameters and observed means for Experiment 1 global analysis.

\begin{tabular}{|c|c|c|c|c|c|c|c|c|c|}
\hline & & \multicolumn{4}{|c|}{ Model } & \multicolumn{2}{|c|}{ TD } & \multicolumn{2}{|c|}{ ASD } \\
\hline & & $b$ & $\mathrm{SE}$ & $t$ & Sig & High & Low & High & Low \\
\hline \multirow{4}{*}{ MFD } & Intercept & 5.40 & 0.02 & 279.08 & $*$ & \multirow{4}{*}{$217(30)$} & \multirow{4}{*}{$220(30)$} & \multirow{4}{*}{$229(40)$} & \multirow{4}{*}{$233(41)$} \\
\hline & Group & -0.05 & 0.04 & -1.24 & & & & & \\
\hline & Frequency & 0.02 & 0.01 & 2.54 & $*$ & & & & \\
\hline & Group X Frequency & $<0.01$ & 0.02 & -0.29 & & & & & \\
\hline \multirow{4}{*}{ MFC } & Intercept & 2.40 & 0.05 & 44.83 & $*$ & \multirow{4}{*}{$10(4)$} & \multirow{4}{*}{$11(4)$} & \multirow{4}{*}{$13(6)$} & \multirow{4}{*}{$14(6)$} \\
\hline & Group & -0.24 & 0.10 & -2.45 & $*$ & & & & \\
\hline & Frequency & 0.02 & 0.02 & 1.33 & & & & & \\
\hline & Group X Frequency & 0.03 & 0.03 & 0.86 & & & & & \\
\hline \multirow{4}{*}{ SRT } & Intercept & 7.81 & 0.06 & 126.81 & $*$ & \multirow{4}{*}{$2243(905)$} & \multirow{4}{*}{$2359(971)$} & \multirow{4}{*}{3174 (1864) } & \multirow{4}{*}{$3223(1723)$} \\
\hline & Group & -0.28 & 0.12 & -2.41 & $*$ & & & & \\
\hline & Frequency & 0.03 & 0.02 & 1.81 & & & & & \\
\hline & Group X Frequency & 0.03 & 0.03 & 0.93 & & & & & \\
\hline \multirow{4}{*}{ SSRT } & Intercept & 6.37 & 0.11 & 57.46 & $*$ & \multirow{4}{*}{$774(727)$} & \multirow{4}{*}{679 (624) } & \multirow{4}{*}{$1483(1615)$} & \multirow{4}{*}{$1555(1574)$} \\
\hline & Group & -0.47 & 0.22 & -2.11 & $*$ & & & & \\
\hline & Frequency & 0.01 & 0.07 & 0.09 & & & & & \\
\hline & Group X Frequency & -0.26 & 0.13 & -1.91 & & & & & \\
\hline
\end{tabular}

$\mathrm{Nb} . \mathrm{MFD}=$ mean fixation duration, $M F C=$ mean fixation count, $S R T=$ sentence reading time, SSRT = second pass sentence reading time. 
Table 2 .

Model parameters for Experiment 1 region analyses.

\begin{tabular}{|c|c|c|c|c|c|c|c|c|c|c|c|c|c|}
\hline & & \multicolumn{4}{|c|}{ Start } & \multicolumn{4}{|c|}{ Target } & \multicolumn{4}{|c|}{ End } \\
\hline & & $b$ & SE & $t$ & Sig & $b$ & SE & $t$ & Sig & $b$ & SE & $t$ & Sig \\
\hline \multirow{4}{*}{$\mathrm{SKIP}^{\dagger}$} & Intercept & & & & & -2.57 & 0.23 & -11.33 & $*$ & & & & \\
\hline & Group & & & & & 0.67 & 0.41 & 1.63 & & & & & \\
\hline & Frequency & & & & & -0.59 & 0.32 & -1.83 & & & & & \\
\hline & $\begin{array}{l}\text { Group X } \\
\text { Frequency }\end{array}$ & & & & & 0.23 & 0.48 & 0.48 & & & & & \\
\hline \multirow{4}{*}{ FFD } & Intercept & & & & & 5.44 & 0.03 & 203.20 & $*$ & & & & \\
\hline & Group & & & & & -0.03 & 0.05 & -0.56 & & & & & \\
\hline & Frequency & & & & & 0.08 & 0.02 & 4.02 & $*$ & & & & \\
\hline & $\begin{array}{l}\text { Group X } \\
\text { Frequency }\end{array}$ & & & & & 0.04 & 0.04 & 1.03 & & & & & \\
\hline \multirow{4}{*}{ SFD } & Intercept & & & & & 5.48 & 0.03 & 180.78 & $*$ & & & & \\
\hline & Group & & & & & -0.05 & 0.05 & -0.86 & & & & & \\
\hline & Frequency & & & & & 0.11 & 0.03 & 4.45 & $*$ & & & & \\
\hline & $\begin{array}{l}\text { Group X } \\
\text { Frequency }\end{array}$ & & & & & 0.01 & 0.05 & 0.26 & & & & & \\
\hline \multirow{4}{*}{ GD } & Intercept & 6.86 & 0.08 & 82.42 & $*$ & 5.62 & 0.04 & 151.52 & $*$ & 6.20 & 0.08 & 75.67 & $*$ \\
\hline & Group & -0.11 & 0.11 & -1.03 & & -0.04 & 0.07 & -0.64 & & -0.07 & 0.11 & -0.60 & \\
\hline & Frequency & 0.00 & 0.02 & -0.12 & & 0.17 & 0.03 & 6.03 & $*$ & 0.03 & 0.04 & 0.71 & \\
\hline & $\begin{array}{l}\text { Group X } \\
\text { Frequency }\end{array}$ & 0.03 & 0.04 & 0.75 & & 0.03 & 0.05 & 0.57 & & 0.10 & 0.07 & 1.35 & \\
\hline \multirow{4}{*}{$\mathrm{TT}$} & Intercept & & & & & 5.86 & 0.05 & 119.92 & $*$ & & & & \\
\hline & Group & & & & & -0.18 & 0.09 & -2.02 & $*$ & & & & \\
\hline & Frequency & & & & & 0.23 & 0.05 & 4.86 & $*$ & & & & \\
\hline & $\begin{array}{l}\text { Group X } \\
\text { Frequency }\end{array}$ & & & & & -0.09 & 0.08 & -1.08 & & & & & \\
\hline \multirow{4}{*}{ SPT } & Intercept & 6.00 & 0.09 & 63.49 & $*$ & 5.55 & 0.06 & 94.29 & $*$ & 6.07 & 0.09 & 67.75 & $*$ \\
\hline & Group & -0.38 & 0.18 & -2.10 & $*$ & -0.16 & 0.12 & -1.36 & & -0.50 & 0.16 & -3.20 & $*$ \\
\hline & Frequency & 0.02 & 0.07 & 0.23 & & 0.15 & 0.08 & 1.85 & & -0.13 & 0.09 & -1.57 & \\
\hline & $\begin{array}{l}\text { Group X } \\
\text { Frequency }\end{array}$ & -0.26 & 0.14 & -1.91 & & 0.04 & 0.15 & 0.26 & & -0.09 & 0.16 & -0.56 & \\
\hline \multirow{4}{*}{$\mathrm{RI}^{\dagger}$} & Intercept & 0.38 & 0.28 & 1.38 & & -1.52 & 0.12 & -12.63 & $*$ & & & & \\
\hline & Group & -0.85 & 0.53 & -1.62 & & -0.22 & 0.21 & -1.03 & & & & & \\
\hline & Frequency & -0.21 & 0.20 & 0.28 & & 0.39 & 0.21 & 1.88 & & & & & \\
\hline & $\begin{array}{l}\text { Group X } \\
\text { Frequency }\end{array}$ & 0.23 & 0.29 & 0.80 & & $\begin{array}{c}- \\
13.00\end{array}$ & 0.39 & -0.33 & & & & & \\
\hline \multirow{4}{*}{$\mathrm{RO}^{\dagger}$} & Intercept & & & & & -1.79 & 0.23 & -7.67 & $*$ & 0.58 & 0.27 & 2.15 & $*$ \\
\hline & Group & & & & & -0.30 & 0.33 & -0.92 & & -0.88 & 0.53 & -1.67 & \\
\hline & Frequency & & & & & -0.11 & 0.18 & -0.59 & & -0.02 & 0.17 & -0.15 & \\
\hline & $\begin{array}{l}\text { Group X } \\
\text { Frequency }\end{array}$ & & & & & -0.42 & 0.35 & -1.22 & & 0.55 & 0.34 & 1.65 & \\
\hline
\end{tabular}

$\uparrow$ Values in the t column for this variable correspond to $z$ values.

Nb. SKIP = skipping, FFD = first fixation duration, $S F D=$ single fixation duration, $G D=$ gaze duration, $T T$ $=$ total time, $S P T=$ second pass time, $R I=$ regressions in, $R O=$ first pass regressions out . 
Table 3.

Observed means (standard deviations) for Experiment 1 region analyses.

\begin{tabular}{|c|c|c|c|c|c|c|c|c|c|c|}
\hline & & & SKIP & FFD & SFD & GD & TT & SPT & RI & RO \\
\hline \multirow{4}{*}{ Start } & \multirow{2}{*}{ TD } & High & & & & $1025(525)$ & & $504(417)$ & $.49(.50)$ & \\
\hline & & Low & & & & $1028(497)$ & & $481(427)$ & $.47(.50)$ & \\
\hline & \multirow{2}{*}{ ASD } & High & & & & $1172(613)$ & & 869 (837) & $.63(.48)$ & \\
\hline & & Low & & & & $1188(707)$ & & $960(874)$ & $.59(.49)$ & \\
\hline \multirow{4}{*}{ Target } & \multirow{2}{*}{ TD } & High & $.14(.35)$ & $225(67)$ & $230(75)$ & $268(129)$ & 334 (184) & $264(180)$ & $.16(.37)$ & $.19(.40)$ \\
\hline & & Low & $.12(.32)$ & $253(81)$ & $260(83)$ & 325 (147) & $400(212)$ & $321(256)$ & $.20(.40)$ & $.15(.36)$ \\
\hline & \multirow{2}{*}{ ASD } & High & $.09(.29)$ & $239(84)$ & $245(88)$ & 281 (114) & $385(231)$ & $386(469)$ & $.18(.38)$ & $.21(.40)$ \\
\hline & & Low & $.07(.26)$ & 257 (94) & $274(97)$ & $335(154)$ & $522(338)$ & $422(353)$ & $.24(.43)$ & $.23(.42)$ \\
\hline \multirow{4}{*}{ End } & \multirow{2}{*}{ TD } & High & & & & $569(372)$ & & $492(342)$ & & $.49(.50)$ \\
\hline & & Low & & & & $611(393)$ & & 441 (444) & & $.55(.50)$ \\
\hline & \multirow{2}{*}{ ASD } & High & & & & $679(485)$ & & 948 (815) & & $.65(.48)$ \\
\hline & & Low & & & & $648(440)$ & & $845(657)$ & & $.63(.48)$ \\
\hline
\end{tabular}

Nb. SKIP = skipping, FFD = first fixation duration, $S F D=$ single fixation duration, $G D=$ gaze duration, $T T$ = total time, $S P T=$ second pass time, $R I=$ regressions in, $R O=$ first pass regressions out . 
Table 4.

Model parameters and observed means for Experiment 2 global analysis.

\begin{tabular}{|c|c|c|c|c|c|c|c|c|c|}
\hline & & \multicolumn{4}{|c|}{ Model } & \multicolumn{2}{|c|}{$\mathrm{TD}$} & \multicolumn{2}{|c|}{ ASD } \\
\hline & & $b$ & SE & $t$ & Sig & High & Low & High & Low \\
\hline \multirow{4}{*}{ MFD } & Intercept & 5.39 & 0.02 & 274.52 & $*$ & \multirow{4}{*}{$218(31)$} & \multirow{4}{*}{$219(30)$} & \multirow{4}{*}{$226(36)$} & \multirow{4}{*}{$226(38)$} \\
\hline & Group & -0.03 & 0.04 & -0.80 & & & & & \\
\hline & Frequency & $<0.01$ & 0.01 & 0.31 & & & & & \\
\hline & $\begin{array}{l}\text { Group X } \\
\text { Frequency }\end{array}$ & 0.01 & 0.01 & 0.48 & & & & & \\
\hline \multirow{4}{*}{ MFC } & Intercept & 2.67 & 0.06 & 47.69 & $*$ & \multirow{4}{*}{$12(4)$} & \multirow{4}{*}{$14(5)$} & \multirow{4}{*}{$18(9)$} & \multirow{4}{*}{$20(11)$} \\
\hline & Group & -0.33 & 0.11 & -2.98 & $*$ & & & & \\
\hline & Frequency & 0.09 & 0.02 & 5.33 & $*$ & & & & \\
\hline & $\begin{array}{l}\text { Group X } \\
\text { Frequency }\end{array}$ & -0.01 & 0.04 & -0.37 & & & & & \\
\hline \multirow{4}{*}{ SRT } & Intercept & 8.07 & 0.07 & 123.41 & $*$ & \multirow{4}{*}{2739 (1069) } & \multirow{4}{*}{3015 (1277) } & \multirow{4}{*}{$4171(2486)$} & \multirow{4}{*}{4687 (2898) } \\
\hline & Group & -0.36 & 0.13 & -2.78 & $*$ & & & & \\
\hline & Frequency & 0.09 & 0.02 & 4.39 & $*$ & & & & \\
\hline & $\begin{array}{l}\text { Group X } \\
\text { Frequency }\end{array}$ & -0.01 & 0.04 & -0.29 & & & & & \\
\hline \multirow{4}{*}{ SSRT } & Intercept & 6.61 & 0.13 & 50.85 & $*$ & \multirow{4}{*}{774 (715) } & \multirow{4}{*}{1064 (959) } & \multirow{4}{*}{2064 (2330) } & \multirow{4}{*}{$2571(2679)$} \\
\hline & Group & -0.66 & 0.26 & -2.56 & $*$ & & & & \\
\hline & Frequency & 0.27 & 0.06 & 4.73 & $*$ & & & & \\
\hline & $\begin{array}{l}\text { Group X } \\
\text { Frequency }\end{array}$ & 0.08 & 0.11 & 0.68 & & & & & \\
\hline
\end{tabular}

Nb. $M F D=$ mean fixation duration, $M F C=$ mean fixation count, SRT = sentence reading time, SSRT = second pass sentence reading time. 
Table 5.

Model parameters for Experiment 2 start, verb, noun and preposition region analyses.

\begin{tabular}{|c|c|c|c|c|c|c|c|c|c|c|c|c|c|c|c|c|c|}
\hline & \multicolumn{4}{|c|}{ Start } & \multicolumn{4}{|c|}{ Verb } & \multicolumn{4}{|c|}{ Noun } & \multicolumn{4}{|c|}{ Preposition } \\
\hline & & $b$ & SE & $t$ & Sig & $b$ & SE & $t$ & Sig & $b$ & $\mathrm{SE}$ & $t$ & Sig & $b$ & SE & $t$ & Sig \\
\hline \multirow{4}{*}{ GD } & Intercept & 5.72 & 0.05 & 107.85 & $*$ & 5.53 & 0.04 & 125.71 & $*$ & 6.08 & 0.06 & 103.02 & $*$ & 5.31 & 0.04 & 146.75 & $*$ \\
\hline & Group & -0.15 & 0.09 & -1.63 & & -0.08 & 0.08 & -1.02 & & -0.13 & 0.10 & -1.38 & & -0.03 & 0.07 & -0.48 & \\
\hline & Frequency & 0.03 & 0.02 & 1.33 & & $<0.01$ & 0.02 & 0.24 & & -0.03 & 0.03 & -0.83 & & 0.03 & 0.03 & 0.95 & \\
\hline & $\begin{array}{l}\text { Group X } \\
\text { Frequency }\end{array}$ & 0.03 & 0.04 & 0.68 & & $<0.01$ & 0.04 & 0.12 & & 0.05 & 0.06 & 0.82 & & $<0.01$ & 0.05 & 0.19 & \\
\hline \multirow{4}{*}{ SPT } & Intercept & 5.61 & 0.07 & 78.10 & $*$ & 5.72 & 0.06 & 92.71 & $*$ & 5.92 & 0.09 & 68.83 & $*$ & 5.60 & 0.07 & 75.76 & $*$ \\
\hline & Group & -0.33 & 0.14 & -2.47 & $*$ & -0.23 & -0.12 & -1.97 & & -0.41 & 0.16 & -2.57 & $*$ & -0.16 & 0.15 & -1.03 & \\
\hline & Frequency & -0.06 & 0.07 & -0.89 & & 0.06 & 0.06 & 1.08 & & 0.18 & 0.07 & 2.40 & * & 0.14 & 0.10 & 1.39 & \\
\hline & $\begin{array}{l}\text { Group X } \\
\text { Frequency }\end{array}$ & -0.07 & 0.13 & -0.55 & & 0.08 & 0.11 & 0.72 & & 0.07 & 0.16 & 0.44 & & 0.08 & 0.21 & 0.38 & \\
\hline \multirow{4}{*}{$\mathrm{RI}^{\dagger}$} & Intercept & -1.40 & 0.27 & -5.23 & $*$ & -0.81 & 0.26 & -.3 .12 & $*$ & -0.94 & 0.24 & -3.90 & $*$ & -0.69 & 0.21 & -3.27 & $*$ \\
\hline & Group & -0.86 & 0.50 & -1.71 & & -0.63 & 0.51 & -1.22 & & -0.77 & 0.47 & -1.64 & & -0.31 & 0.40 & -0.78 & \\
\hline & Frequency & 0.17 & 0.15 & 1.13 & & 0.09 & 0.14 & 0.65 & & 0.34 & 0.16 & 2.08 & $*$ & 0.55 & 0.16 & 3.47 & $*$ \\
\hline & $\begin{array}{l}\text { Group X } \\
\text { Frequency }\end{array}$ & -0.47 & 0.26 & -1.78 & & 0.32 & 0.27 & 1.21 & & 0.26 & 0.32 & 0.82 & & 0.07 & 0.31 & 0.22 & \\
\hline \multirow{4}{*}{$\mathrm{RO}^{\dagger}$} & Intercept & & & & & -2.56 & 0.20 & -12.57 & $*$ & -2.07 & 0.18 & -11.26 & $*$ & -2.45 & 0.21 & -11.58 & $*$ \\
\hline & Group & & & & & 0.27 & 0.39 & 0.68 & & 0.02 & 0.34 & 0.07 & & -0.21 & 0.35 & -0.61 & \\
\hline & Frequency & & & & & -0.03 & 0.18 & -0.17 & & 0.07 & 0.18 & 0.39 & & 0.03 & 0.32 & 0.10 & \\
\hline & $\begin{array}{l}\text { Group X } \\
\text { Frequency }\end{array}$ & & & & & -0.44 & 0.37 & -1.19 & & 0.16 & 0.30 & 0.53 & & -0.23 & 0.51 & -0.45 & \\
\hline
\end{tabular}

${ }^{\dagger}$ Note that the values in the $t$ column for this variable correspond to $\mathrm{z}$ values.

$N b . G D=$ gaze duration, $S P T=$ second pass time, $R I=$ regressions in, $R O=$ first pass regressions out. 
Table 6

Model parameters for Experiment 2 pre-target, target, post target and end regions.

\begin{tabular}{|c|c|c|c|c|c|}
\hline & \multicolumn{4}{|c|}{ Pre-target } \\
\hline & & $b$ & SE & $t$ & Sig \\
\hline \multirow{4}{*}{ SKIP $^{\dagger}$} & Intercept & -3.25 & 0.29 & -10.96 & $*$ \\
\hline & Group & 0.33 & 0.46 & 0.72 & \\
\hline & Frequency & 0.58 & 0.35 & 1.65 & \\
\hline & Group X Frequency & -0.02 & 0.52 & -0.05 & \\
\hline \multirow{4}{*}{ FFD } & Intercept & 5.29 & 0.19 & 273.44 & * \\
\hline & Group & 0.06 & 0.04 & 1.50 & \\
\hline & Frequency & -0.02 & 0.01 & -1.25 & \\
\hline & Group X Frequency & 0.01 & 0.03 & 0.43 & \\
\hline \multirow{4}{*}{ SFD } & Intercept & 5.33 & 0.02 & 233.44 & * \\
\hline & Group & 0.02 & 0.04 & 0.45 & \\
\hline & Frequency & -0.01 & 0.02 & -0.73 & \\
\hline & Group X Frequency & 0.02 & 0.03 & 0.53 & \\
\hline \multirow{4}{*}{ GD } & Intercept & 5.53 & 0.03 & 166.66 & * \\
\hline & Group & -0.09 & 0.06 & -1.52 & \\
\hline & Frequency & 0.01 & 0.02 & 0.60 & \\
\hline & Group X Frequency & -0.03 & 0.05 & -0.70 & \\
\hline \multirow{4}{*}{ GP } & Intercept & 5.68 & 0.05 & 108.09 & * \\
\hline & Group & -0.18 & 0.10 & -1.79 & \\
\hline & Frequency & -0.02 & 0.03 & -0.82 & \\
\hline & Group X Frequency & -0.01 & 0.04 & -0.19 & \\
\hline \multirow{4}{*}{ TT } & Intercept & 5.96 & 0.07 & 90.57 & $*$ \\
\hline & Group & -0.33 & 0.13 & -2.62 & * \\
\hline & Frequency & 0.11 & 0.04 & 2.52 & * \\
\hline & Group X Frequency & -0.01 & 0.07 & -0.10 & \\
\hline \multirow{4}{*}{ SPT } & Intercept & 5.75 & 0.06 & 90.30 & * \\
\hline & Group & -0.35 & 0.13 & -2.76 & * \\
\hline & Frequency & 0.15 & 0.07 & 2.32 & $*$ \\
\hline & Group X Frequency & 0.14 & 0.13 & 1.15 & \\
\hline \multirow{4}{*}{$\mathrm{RI}^{\dagger}$} & Intercept & 0.07 & 0.18 & -4.07 & * \\
\hline & Group & -0.49 & 0.35 & -1.39 & \\
\hline & Frequency & 0.43 & 0.12 & 3.57 & $*$ \\
\hline & Group X Frequency & 0.11 & 0.23 & 0.46 & \\
\hline \multirow{4}{*}{$\mathrm{RO}^{\dagger}$} & Intercept & -2.30 & 0.22 & -10.30 & $*$ \\
\hline & Group & -0.61 & 0.41 & -1.46 & \\
\hline & Frequency & -0.15 & 0.19 & -0.79 & \\
\hline & Group X Frequency & 0.08 & 0.32 & 0.26 & \\
\hline
\end{tabular}

\begin{tabular}{cccc}
\multicolumn{4}{c}{ Target } \\
\hline$b$ & SE & $t$ & Sig \\
\hline-2.27 & 0.25 & -9.21 & $*$ \\
0.82 & 0.39 & 2.13 & $*$ \\
-0.25 & 0.19 & -1.28 & \\
0.13 & 0.33 & 0.38 & \\
\hline 5.42 & 0.03 & 215.70 & $*$ \\
0.02 & 0.05 & 0.42 & \\
0.02 & 0.02 & 1.24 & \\
-0.01 & 0.03 & -0.40 & \\
\hline 5.46 & 0.03 & 186.04 & $*$ \\
0.02 & 0.06 & 0.29 & \\
0.06 & 0.02 & 2.49 & $*$ \\
0.02 & 0.04 & 0.41 & \\
\hline 5.58 & 0.03 & 172.10 & $*$ \\
-0.01 & 0.06 & -0.17 & \\
0.09 & 0.03 & 3.00 & $*$ \\
$<0.01$ & 0.04 & 0.02 & \\
\hline 5.75 & 0.04 & 130.58 & $*$ \\
-0.07 & 0.08 & -0.79 & \\
0.10 & 0.03 & 3.07 & $*$ \\
0.01 & 0.05 & 0.21 & \\
\hline 5.82 & 0.05 & 107.04 & \\
-0.18 & 0.10 & -1.73 & \\
0.18 & 0.04 & 4.41 & $*$ \\
-0.04 & 0.05 & -0.85 & \\
\hline 5.62 & 0.06 & 94.93 & $*$ \\
-0.33 & 0.11 & -2.95 & $*$ \\
0.13 & 0.06 & 1.95 & \\
0.11 & 0.13 & 0.84 & \\
\hline-1.40 & 0.17 & -8.90 & $*$ \\
-0.12 & 0.28 & -0.42 & $*$ \\
0.31 & 0.14 & 2.15 & $*$ \\
-0.08 & 0.27 & -0.28 & \\
\hline-1.72 & 0.16 & -10.57 & $*$ \\
-0.15 & 0.32 & -0.46 & \\
0.12 & 0.17 & 0.69 & \\
-0.10 & 0.30 & -0.33 & \\
& & & \\
& \\
\hline
\end{tabular}

\begin{tabular}{cccc}
\multicolumn{4}{c}{ Post Target } \\
\hline$b$ & SE & $t$ & Sig \\
\hline-1.67 & 0.36 & -4.64 & $*$ \\
0.09 & 0.41 & 0.23 & \\
-0.29 & 0.20 & -1.44 & \\
0.21 & 0.27 & 0.78 & \\
\hline 5.40 & 0.03 & 200.86 & $*$ \\
-0.02 & 0.05 & -0.29 & \\
0.02 & 0.02 & 0.94 & \\
-0.03 & 0.04 & -0.79 & \\
\hline 5.44 & 0.03 & 176.97 & $*$ \\
-0.04 & 0.06 & -0.66 & \\
$<0.01$ & 0.03 & 0.03 & \\
-0.03 & 0.06 & -0.53 & \\
\hline 5.62 & 0.05 & 124.41 & $*$ \\
-0.10 & 0.08 & -1.18 & \\
0.01 & 0.03 & 0.42 & \\
0.05 & 0.06 & 0.77 & \\
\hline 60.40 & 0.07 & 85.15 & $*$ \\
-0.29 & 0.13 & -2.13 & $*$ \\
0.15 & 0.05 & 2.86 & $*$ \\
0.05 & 0.10 & 0.50 & \\
\hline 5.90 & 0.06 & 94.07 & $*$ \\
-0.30 & 0.12 & -2.63 & $*$ \\
0.08 & 0.03 & 2.32 & $*$ \\
0.03 & 0.07 & 0.37 & \\
\hline 5.69 & 0.07 & 83.54 & $*$ \\
-0.25 & 0.14 & -1.83 & \\
0.06 & 0.08 & 0.74 & \\
-0.11 & 0.16 & -0.71 & \\
\hline-1.19 & 0.17 & -7.16 & $*$ \\
-0.43 & 0.25 & -1.72 & \\
0.04 & 0.14 & 0.32 & \\
0.28 & 0.26 & 1.07 & \\
\hline-0.95 & 0.18 & -5.34 & $*$ \\
-0.02 & 0.28 & -0.06 & \\
0.40 & 0.13 & 3.07 & $*$ \\
-0.03 & 0.25 & -0.13 & \\
& & & \\
& \\
\hline & \\
\hline
\end{tabular}

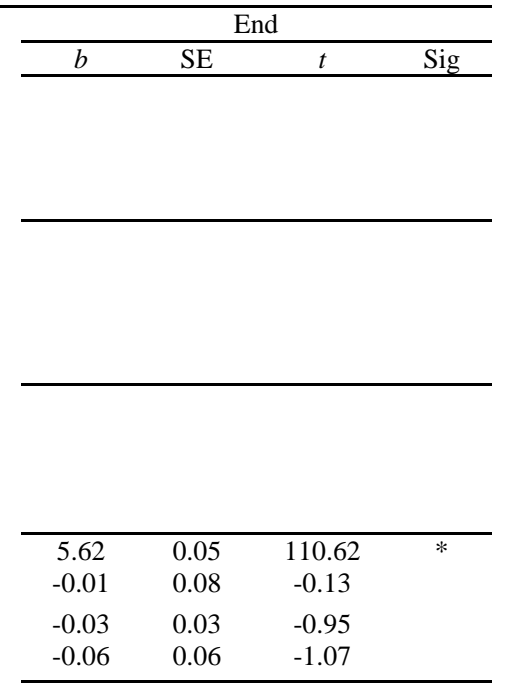

$\dagger$ Note that the values in the $t$ column for this variable correspond to $\mathrm{z}$ values.

Nb. SKIP = skipping, FFD = first fixation duration, $S F D=$ single fixation duration, $G D=$ gaze duration, $T T=$ total time, $S P T=$ second pass time, $R I=$ regressions in, $R O=$ first pass regressions out. 
Table 7.

Observed means (standard deviations) for Experiment 2 region analyses.

\begin{tabular}{|c|c|c|c|c|c|c|c|c|c|c|c|}
\hline & & & SKIP & FFD & SFD & GD & GP & TT & SPT & RI & RO \\
\hline \multirow{4}{*}{ Start } & \multirow{2}{*}{ TD } & High & & & & 304 (137) & & & 294 (178) & .21(.41) & \\
\hline & & Low & & & & 325 (196) & & & $266(159)$ & $.20(.40)$ & \\
\hline & \multirow{2}{*}{ ASD } & High & & & & 357 (167) & & & 490 (403) & $.31(.47)$ & \\
\hline & & Low & & & & 364 (176) & & & $542(623)$ & $.38(.49)$ & \\
\hline \multirow{4}{*}{ Verb } & \multirow{2}{*}{$\mathrm{TD}$} & High & & & & $268(122)$ & & & $321(204)$ & $.26(.44)$ & $.11(.32)$ \\
\hline & & Low & & & & 272 (129) & & & $368(218)$ & $.32(.47)$ & $.10(.30)$ \\
\hline & \multirow{2}{*}{ ASD } & High & & & & 297 (126) & & & $466(333)$ & $.42(.49)$ & $.07(.26)$ \\
\hline & & Low & & & & $301(139)$ & & & $527(513)$ & $.41(.50)$ & $.09(.29)$ \\
\hline \multirow{4}{*}{ Noun } & \multirow{2}{*}{ TD } & High & & & & $469(261)$ & & & $405(315)$ & $.23(.42)$ & $.14(.34)$ \\
\hline & & Low & & & & $472(259)$ & & & 495 (389) & $.31(.46)$ & $.15(.36)$ \\
\hline & \multirow{2}{*}{ ASD } & High & & & & $564(302)$ & & & $773(714)$ & $.37(.48)$ & $.15(.36)$ \\
\hline & & Low & & & & $553(332)$ & & & $864(751)$ & $.41(.49)$ & $.14(.35)$ \\
\hline \multirow{4}{*}{ Prep } & \multirow{2}{*}{ TD } & High & & & & $223(105)$ & & & 259 (144) & $.29(.45)$ & $.38(.49)$ \\
\hline & & Low & & & & $229(91)$ & & & $328(202)$ & $.40(.49)$ & $.47(.50)$ \\
\hline & \multirow{2}{*}{ ASD } & High & & & & $236(106)$ & & & $364(253)$ & $.09(.28)$ & $.09(.29)$ \\
\hline & & Low & & & & 241 (118) & & & 447 (327) & $.09(.28)$ & $.11(.32)$ \\
\hline \multirow{4}{*}{$\begin{array}{l}\text { Pre } \\
\text { target }\end{array}$} & \multirow{2}{*}{ TD } & High & $.07(.26)$ & $212(50)$ & $216(51)$ & $261(115)$ & 307 (164) & 356 (197) & 291 (179) & $.27(.44)$ & $.11(.32)$ \\
\hline & & Low & $.09(.28)$ & $209(48)$ & 214 (48) & 262 (117) & 299 (167) & 408 (236) & $373(233)$ & $.36(.48)$ & $.10(.30)$ \\
\hline & \multirow{2}{*}{ ASD } & High & $.07(.26)$ & $203(57)$ & $212(63)$ & 288 (138) & 381 (269) & $564(485)$ & $546(439)$ & $.37(.48)$ & $.20(.40)$ \\
\hline & & Low & $.08(.27)$ & $198(52)$ & $210(73)$ & 299 (144) & $373(234)$ & $616(447)$ & $582(518)$ & $.44(.50)$ & $.17(.37)$ \\
\hline \multirow{4}{*}{ Target } & \multirow{2}{*}{ TD } & High & $.22(.41)$ & $239(84)$ & $242(88)$ & $276(116)$ & 328 (178) & $322(160)$ & $253(144)$ & $.22(.41)$ & $.16(.37)$ \\
\hline & & Low & $.19(.39)$ & $243(82)$ & 259 (98) & $300(119)$ & 364 (198) & $386(203)$ & 315 (193) & $.26(.44)$ & $.18(.38)$ \\
\hline & \multirow{2}{*}{ ASD } & High & $.13(.34)$ & $234(82)$ & 242 (87) & 278 (112) & $375(390)$ & 401 (277) & 445 (389) & $.20(.40)$ & $.18(.38)$ \\
\hline & & Low & $.10(.30)$ & $243(90)$ & 254 (93) & 305 (127) & 407 (306) & $503(355)$ & $474(383)$ & $.25(.43)$ & $.21(.41)$ \\
\hline \multirow{4}{*}{$\begin{array}{l}\text { Post } \\
\text { Target }\end{array}$} & \multirow{2}{*}{$\mathrm{TD}$} & High & $.27(.44)$ & $236(97)$ & $244(105)$ & $298(154)$ & $421(356)$ & $361(210)$ & $311(235)$ & $.22(.42)$ & $.27(.45)$ \\
\hline & & Low & $.25(.43)$ & 237 (95) & 244 (105) & $312(175)$ & $541(472)$ & $391(221)$ & $321(281)$ & $.25(.43)$ & $.35(.48)$ \\
\hline & \multirow{2}{*}{ ASD } & High & $.25(.43)$ & $236(90)$ & $250(104)$ & $339(180)$ & $684(816)$ & $533(381)$ & $482(378)$ & $.32(.47)$ & $.28(.45)$ \\
\hline & & Low & $.21(.41)$ & 248 (107) & 253 (107) & $340(201)$ & 890 (1256) & $570(415)$ & $565(522)$ & $.31(.46)$ & $.35(.48)$ \\
\hline \multirow{4}{*}{ End } & \multirow{2}{*}{$\mathrm{TD}$} & High & & & & 349 (205) & & & $345(314)$ & $674(505)$ & $.54(.50)$ \\
\hline & & Low & & & & 324 (199) & & & 338 (204) & $644(452)$ & $.60(.49)$ \\
\hline & \multirow{2}{*}{ ASD } & High & & & & 342 (227) & & & & & $.67(.47)$ \\
\hline & & Low & & & & 349 (236) & & & & & $.72(.45)$ \\
\hline
\end{tabular}

Nb. Prep = preposition, $S K I P=$ skipping, FFD = first fixation duration, $S F D=$ single fixation duration, $G D=$ gaze duration, $T T=$ total time, $S P T$ $=$ second pass time, $R I=$ regressions in, $R O=$ first pass regressions out . 
Acknowledgements

This research was funded by the Mayflower scholarship, provided by the Faculty of Health, Life and Mathematical Sciences at the University of Southampton and was completed in part for the first author's doctoral thesis. We would like to thank all of the postgraduates from the Centre of Vision and Cognition who assisted with data collection and all of the volunteers who participated. 